\title{
Spray-drying of inhalable, multifunctional formulations for the treatment of biofilms formed in cystic fibrosis
}

Nashrawan Lababidi ${ }^{1}$, Eric Ofosu Kissi ${ }^{2,3}$, Walid A. M. Elgaher ${ }^{4}$, Valentin Sigal ${ }^{1}$, Jörg Haupenthal ${ }^{4}$, Bianca C. Schwarz ${ }^{5}$, Anna K. H. Hirsch ${ }^{4,6}$, Thomas Rades ${ }^{3}$, Marc Schneider ${ }^{1, *}$

${ }^{1}$ Department of Pharmacy, Biopharmaceutics and Pharmaceutical Technology, Saarland University, Campus C4 1, 66123 Saarbrücken, Germany,

${ }^{2}$ Department of Pharmacy, Faculty of Mathematics and Natural Sciences, University of Oslo, 0316 Oslo, Norway

${ }^{3}$ Department of Pharmacy, Faculty of Health and Medical Science, University of Copenhagen, Universitetsparken 2, DK-2100 Copenhagen, Denmark

${ }^{4}$ Helmholtz Institute for Pharmaceutical Research Saarland (HIPS) - Helmholtz Centre for Infection Research (HZI), Department of Drug Design and Optimization, Campus E8 1, 66123, Saarbrücken, Germany

${ }^{5}$ Pferdeklinik Altforweiler, Raiffeisenstraße 100, 66802 Überherrn, Germany

${ }^{6}$ Department of Pharmacy, Medicinal Chemistry, Saarland University, Campus E8 1, 66123 Saarbrücken, Germany

* Corresponding author:

Prof. Dr. Marc Schneider

Address: Biopharmaceutics and Pharmaceutical Technology

Campus C4 1, 66123 Saarbrücken

Email: Marc.Schneider@uni-saarland.de

Phone: +49 (0) 681 302-2438

Fax: $+49(0) 681302-2028$ 


\begin{abstract}
:
Cystic fibrosis (CF) is a serious lung disease, commonly susceptible to Pseudomonas aeruginosa colonization. The dense mucus together with biofilm formation limit drug permeability and prevent the drug from reaching the site of action, causing treatment failure of the bacterial infection. Besides the use of antibiotics, the mucolytic agent $N$-acetylcysteine (NAC) is recommended to be co-administered in the treatment of CF. Although several formulations have been developed for inhalation therapy to improve the pulmonary condition in CF patients, there is still no comprehensive study on a combined multifunctional dry powder formulation of antibiotics with NAC. In this work, we developed an innovative multifunctional dry powder inhaler (DPI) formulation based on salt formation between NAC and antibiotics and characterized their solid state properties and physical stability. NAC could be spray dried together with three different antibiotics, azithromycin (Azi), tobramycin (Tobra) and ciprofloxacin (Cipro), without the use of organic solvents to form Azi/NAC, Tobra/NAC and Cipro/NAC DPI formulations. Solid-state characterization of these DPI formulations showed that they were amorphous after spray drying. Azi/NAC and Tobra/NAC form co-amorphous salt systems that were physically stable under storage at stress conditions. For particle characterization, the obtained mass median aerodynamic diameters were in a suitable range for inhalation $(<5.0 \mu \mathrm{m})$. The multifunctional antibiotic/NAC formulations conserved or improved the antibiotic susceptibility and showed promising results regarding the inhibition of $P$. aeruginosa PA14 biofilm formation.
\end{abstract}

Keywords: Salt formation, antibiotics, co-amorphous drug delivery, inhalation, bacterial infection, dry-powder formulation 


\section{Introduction}

Cystic fibrosis (CF) is a congenital lethal chronic disease in which thick and sticky mucus is secreted in different organs such as the pancreatic duct, intestine, and the lung [1]. The abnormal thickness of the mucus causes problems such as intestinal blockage and a reduced clearance of the airways. Infections by Pseudomonas aeruginosa that built resistant biofilms in the lung are common in the later stages of the disease [2]. According to recent statistics, approximately 70,000 to 100,000 children and adults around the world suffer from $\mathrm{CF}[\underline{3}, \underline{4}]$.

The strategies for treating CF in the lung partly rely on the application of inhaled antibiotics in high doses using nebulizers for the treatment of early infections and inhibition of biofilm formation, either as monotherapy or in addition to oral/IV antibiotic administration as combination therapy $[\underline{5}, \underline{6}]$. The guidelines for treating CF recommend co-administration of a mucolytic agent to fluidize the mucus, as well as of osmotic compounds like mannitol, to preserve hydration of the airways $[\underline{7}, \underline{8}]$. The key advantage of inhalation of antibiotics is to reduce systemic side-effects by avoiding systemic circulation [9-12]. Currently, only few antibiotics, namely tobramycin (Tobi ${ }^{\circledR}$, Novartis $A G$, Switzerland), aztreonam (Cayston ${ }^{\circledR}$; Gilead Sciences, USA), and colistimethate sodium (Colomycin ${ }^{\circledR}$, Promixin $\left.{ }^{\circledR}\right)$ are available on the market for application via nebulization [13-17]. Nebulization, however, has several drawbacks including the potential for the nebulizer itself to act as a source of bacterial infection, drug loss during the aerosolization process, a long administration time, and a reduced performance of the nebulizer over time [18-24]. In contrast to nebulization, the use of drypowder inhalers (DPIs) reduces treatment expenses and increases patient convenience, and thus therapy adherence. In addition, DPIs do not require cold temperature storage of the formulation, as is the case for nebulizers [25], have a lower contamination probability and allow higher doses to be delivered [26].

$N$-acetylcysteine (NAC) has antimicrobial properties by decreasing biofilm formation and diminishing the production of extracellular polysaccharide matrix [27-29]. NAC has a mucolytic 
effect by cleaving the disulfide bonds in mucins leading to reduced mucus viscosity [료, $\underline{30}, \underline{31}]$. Based on the essential need to combine antibiotics and mucolytics for an efficient therapy, the aim of this study was to combine these drugs in one formulation. This combination could thus potentially facilitate the treatment of CF patients. In the present study, we describe the preparation of a spray-dried powder for inhalation composed of antibiotics and NAC.

Spray drying follows the thermodynamic pathway of producing amorphous drugs [32]. Whilst amorphous drugs may still have some residual short-range molecular order [32], they do not have any positional and orientation long-range order (which would reduce the free energy of the material), and are thus physically unstable and can recrystallize. This is because the molecules are mobile, even in their glassy form (due to $\beta$-relaxation), i.e., even at temperatures below their glass transition temperature [33]. The physical stability of amorphous drugs, however, can be improved by formulating them as glass solutions or amorphous solid dispersions $[\underline{34}, \underline{35}]$. Polymeric glass solutions stabilize the amorphous drugs by molecularly incorporating the drug into an amorphous polymeric matrix [느, 35]. Non-polymeric glass solutions (so called co-amorphous systems) stabilize the drug molecules by means of another small molecule or excipient via co-amorphization. Co-amorphization is a process that involves amorphizing a crystalline drug together with another also initially crystalline low molecular weight material, the so-called coformer (which can be a second drug or an excipient) [므, $\underline{37}]$. Co-amorphous systems thus contain two components but are characterized by a single glass transition temperature $\left(T_{g}\right)[\underline{37}, \underline{38}]$. Co-amorphization results in the formation of co-amorphous salts and has an added advantage as it improves the solubility of the drug by two solid-state conversions, namely salt formation and amorphization [39].

In this study, after producing multifunctional DPI formulations, solid-state characterization and physical stability of the obtained multifunctional DPI formulations were investigated as well as their aerodynamic properties and disintegration behaviour. To understand the potential for mucus interaction, the influence of the multifunctional DPI formulation on the viscosity of 
mucus was studied. Finally, the activities of the antibiotics on bacteria and their biofilm were tested.

\section{Material and methods}

\subsection{Materials}

D-mannitol $\quad(\geq 98 \%) \quad(\mathrm{MW}=182.172 \mathrm{~g} / \mathrm{mol}), \quad N$-acetylcysteine $\quad(\mathrm{MW}=163.19 \mathrm{~g} / \mathrm{mol}$. $\left.\mathrm{p} K_{\mathrm{a}}=3.82\right)$, L-leucine $(\mathrm{MW}=131.18 \mathrm{~g} / \mathrm{mol})$, agarose, azithromycin $(\mathrm{MW}=748.98 \mathrm{~g} / \mathrm{mol}$, $\mathrm{p} K_{\mathrm{a}}=12.43$ [40]), ciprofloxacin $\left(\mathrm{MW}=331.346 \mathrm{~g} / \mathrm{mol}, \mathrm{p} K_{\mathrm{a}}=8.68\right.$ [40] $)$ and tobramycin (MW $=467.515 \mathrm{~g} / \mathrm{mol}, \mathrm{p} K_{\mathrm{a}}=12.57$ [40]) were obtained from Sigma Aldrich (Steinheim, Germany). Nitrocellulose membrane was a gift from Fisher Scientific GmbH (Schwelten, Germany). Pulmonary horse mucus was obtained after bronchoalveolar lavage (BAL) of horses (Pferdeklinik Altforweiler, Germany).

Materials for preparation of proteose peptone glucose ammonium salts (PPGAS) medium: ammonium chloride (VWR, Darmstadt Germany), potassium chloride (Grüssing GmbH, Filsum, Germany), Tris-HCl (Carl Roth, Karlsruhe, Germany), anhydrous magnesium sulfate (Grüssing GmbH, Filsum, Germany), tryptone (BD Biosciences), glucose (Carl Roth, Karlsruhe, Germany). Lysogeny broth (LB) medium (Lennox) was purchased from Carl Roth (Karlsruhe, Germany). P. aeruginosa PA14 strain was kindly provided by the Häußler Lab (Helmholtz Centre for Infection Research, Germany).

\subsection{Preparation of multifunctional DPI formulations}

The multifunctional DPI formulations were produced by using a BÜCHI B-290 Spray Dryer (Flawil, Switzerland). NAC and the antibiotics were separately dissolved in Milli-Q water under magnetic stirring. The NAC solution was added slowly to the antibiotics solution at different ratios (Table 1). The mixed solution was left for $10 \mathrm{~min}$ until it became clear and L-leucine was added to improve the aerodynamic properties and reduce cohesion of the spray-dried particles [41]. The amount of L-leucine (LEU), given in Table 1, was determined in preliminary studies. The mixed solution was adjusted to gain a total concentration of all solid substances of $1 \mathrm{wt}$. \% 
for spray drying. For quantification, $100 \mu \mathrm{L}$ of a $5 \mathrm{mg} / \mathrm{mL}$ rhodamine B-ethanol solution was added for each $100 \mathrm{mg}$ of dry substance in the feeding solution for spraying. The inlet temperature was $80{ }^{\circ} \mathrm{C}$ and the gas flow rate $35 \mathrm{~m}^{3} / \mathrm{h}$ (aspirator was set to $100 \%$ ). The air volume flow was $1050 \mathrm{~L} / \mathrm{h}$ (gas rotameter was set to $50 \mathrm{~mm}$ ) and the feeding solution had a flow of $\sim 3$ $\mathrm{mL} / \mathrm{min}$. All formulations were spray dried with compressed air. Then, the obtained powders were collected and stored in a desiccator at room temperature. All formulations were spray dried in triplicate. The multifunctional DPI formulations obtained were ciprofloxacin/NAC (Cipro/NAC), azithromycin/NAC (Azi/NAC), tobramycin/NAC (Tobra/NAC).

\subsection{Solid-state characterisation}

An X-ray powder diffractometer (XRPD) was used to determine the solid-state form of the DPI formulations. The measurements were performed using an X'Pert PRO XRPD (PANalytical, Almelo, The Netherlands). In brief, the crystalline starting materials and DPI formulations were exposed to $\mathrm{Cu} \mathrm{K} \alpha$ radiation (1.5418 $\AA$ ) which was generated using a voltage and current of 45 $\mathrm{kV}$ and $40 \mathrm{~mA}$, respectively. The samples were scanned in reflectance mode from $0-35^{\circ} 2 \theta$. Thermal analysis was performed using a modulated differential scanning calorimeter (mDSC) (Discovery, TA Instruments, New Castle, USA). Approximately $4 \mathrm{mg}$ of the crystalline samples and DPI formulations were crimped into a $\mathrm{T}_{\text {zero }}$ pan and covered with a $\mathrm{T}_{\text {zero }}$ lid. The experiments were conducted in a modulated temperature mode using a heating rate of $2{ }^{\circ} \mathrm{C} / \mathrm{min}$, an amplitude of $0.212{ }^{\circ} \mathrm{C}$ and period of $40 \mathrm{~s}$. For the NAP, Tobra, and Azi crystalline samples quench cooling (QC) was performed before determining $T_{g}$. Crystalline ciprofloxacin was converted to the amorphous form by ball milling before determining $T_{g}$. For the DPI formulations, the samples were analysed from $-20{ }^{\circ} \mathrm{C}$ to $20^{\circ} \mathrm{C}$ above the respective $T_{g}$. A theoretical estimate of the $T_{g}$ of the co-amorphous DPI formulations was made using the Fox equation [42]: 


$$
\frac{1}{T_{g 12}}=\frac{w_{1}}{T_{g 1}}+\frac{w_{2}}{T_{g 2}}
$$

Where $T_{g 12}$ is the theoretical $T_{g}$ of the co-amorphous formulation, $T_{g 1}$ and $T_{g 2}$ are the experimental $T_{g}$ of the neat amorphous drug and NAC respectively, and $w_{1}$ and $w_{2}$ are weight fractions of the drug and NAC, respectively.

\subsection{Morphology of the multifunctional DPI formulations}

For morphology analysis, a scanning electron microscope EVO HD 15 from Zeiss (Jena, Germany) was used. Each of the multifunctional DPI formulations was spread on an individual carbon disc and sputter-coated with a $10 \mathrm{~nm}$ gold layer using a Quorum Q150R ES sputter coater (Laughton, UK).

\subsection{Determination of in vitro aerodynamic behavior}

For examination of the aerodynamic properties, the multifunctional DPI formulations were applied to a Next Generation Impactor (NGI) (Copley Scientific, Nottingham, UK). Before the experiment, the impactor pans were coated with a Brij-coating consisting of 4 parts $15 \%$ Brij 35 in ethanol in 6 parts glycerol; $10 \mathrm{~mL}$ of Milli-Q water was filled into the pre-separator. For every experiment, a hard gelatin capsule (size 3) was filled with approximately $20 \mathrm{mg}$ formulation. The air flow for application was set to $60 \mathrm{~L} / \mathrm{min}$, controlled by a M1A flowmeter (Copley Scientific, Nottingham, UK). The capsules were placed in a HandiHaler (Boehringer Ingelheim, Ingelheim, Germany) and were pierced. Aerosolization of the powder was achieved by applying a 4 second gas flow by a vacuum pump and critical flow controller (both Erweka, Heusenstamm, Germany). Then, the powders deposited in the different NGI cups were quantified by dissolving with a defined amount of water and analyzing the fluorescence signal of rhodamine B using a Tecan reader infinite 200 (Tecan, Männedorf, Switzerland). For each formulation, an individual calibration curve was prepared and the whole formulation was analyzed using an excitation wavelength of $565 \mathrm{~nm}$ and an emission wavelength of $625 \mathrm{~nm}$. All experiments of every formulation were carried out in triplicate. 


\subsection{Disintegration behavior of multifunctional DPI formulations}

$0.1 \%$ agarose gels were prepared by dissolving agarose in hot water for $30 \mathrm{~min}$ and pouring the solution into Petri dishes. The gel was left overnight to cool down. Spray-dried multifunctional DPI formulations were spread on top of a nitrocellulose membrane using a Penn-Century device (Wyndmoor, USA). Then, the nitrocellulose membrane pieces were placed on top of the gel pad for a pre-determined amount of time $(5 \mathrm{~min}, 10 \mathrm{~min}$, and $30 \mathrm{~min})$ to determine the disintegration behavior of the formulations over time. Afterwards, the membranes were removed from the gel pads and analyzed by SEM. All experiments were carried out in triplicate.

\subsection{Determination of the rheological properties of mucus after applying the multifunctional DPI formulations}

The viscoelastic properties of pulmonary horse mucus in the presence and without the formulations were determined using a Kinexus rotational viscometer (Malvern, Malvern, UK). Pulmonary horse mucus was used as an alternative to human mucus due to its availability in quantities necessary for conducting the experiments. The viscosity of the pulmonary horse mucus (Pferdeklinik Altforweiler, Germany) without treatment with the multifunctional DPI formulations was measured as a control. The effect of pure NAC on the viscosity of mucus was also measured. To investigate the effect of the formulations, every mucus sample (500 $\mu \mathrm{L})$ was treated with $100 \mu \mathrm{L}$ dissolved formulation adjusting the NAC content to $0.1 \%$. The viscous behaviour was measured using a cone-plate geometry with $0.5^{\circ}$ angle $(\mathrm{C} 60 / 0.5)$ at different shear stress rates $(0.02-100 \mathrm{~Pa})$. Measurements were performed at room temperature in triplicate.

\subsection{Stability of the multifunctional DPI formulations}

\subsubsection{Physical stability}

Physical stability (conversion from the amorphous form to the crystalline state) of the multifunctional DPI formulations was analyzed by XRPD after storage of the samples for 6 
weeks at $65^{\circ} \mathrm{C}$ (i.e., in the glassy state) and for 20 minutes at $125^{\circ} \mathrm{C}$ (i.e., in the supercooled liquid state).

\subsubsection{Morphological stability determined by SEM}

For stability analyses, a scanning electron microscope EVO HD 15 from Zeiss (Jena, Germany) was employed. For each formulation, 2 batches were prepared. One batch was stored in a desiccator in the presence of silica gel at room temperature and one at ambient conditions at room temperature in the dark. These storage conditions were chosen to enable a comparison between formulations that were stored at dry conditions $(\sim 0 \% \mathrm{RH})$ and at ambient/humid conditions $(45 \% \mathrm{RH})$. The formulations were investigated regarding their morphological changes directly after preparation, and after two weeks, three months, and nine months of storage.

\subsection{Pseudomonas aeruginosa biofilm assay}

Determination of the effects of the multifunctional DPI formulations on the overall biofilm mass was performed using the crystal violet $(\mathrm{CV})$ assay according to reported procedures with slight modifications [4ㄴ, $\underline{44}$ ]. P. aeruginosa PA14 was cultivated in 96-well plates using PPGAS medium (0.02 M NH $4 \mathrm{Cl}, 0.02 \mathrm{M} \mathrm{KCl}, 0.12 \mathrm{M}$ Tris-HCl, $0.0016 \mathrm{M} \mathrm{MgSO}_{4}, 1 \%$ Tryptone, 0.5\% glucose, $\mathrm{pH}$ 7.2). Two $\mu \mathrm{L}$ of the multifunctional DPI formulations stock solution in water were added to $198 \mu \mathrm{L}$ of the bacterial culture to give a total volume of $200 \mu \mathrm{L}$ (final concentration equals $1 \%$ of the stock solution concentration). Neat antibiotics: azithromycin ( 0.03 and 1.0 $\mathrm{mg} / \mathrm{mL}$ in DMSO), ciprofloxacin $(0.01$ and $0.03 \mathrm{mg} / \mathrm{mL}$ in DMSO), tobramycin $(0.01,0.03$, and $1.0 \mathrm{mg} / \mathrm{mL}$ in water) as well as NAC (aqueous solutions at the same concentrations as in the multifunctional DPI formulations) were used as references. DMSO $1 \%$ was used as a control. Experiments were performed in triplicate. Graphical illustrations represent the mean values and error bars denote the standard deviation.

\subsection{Extracellular DNA (eDNA) assay}


The impact of multifunctional DPI formulations on eDNA was assessed as previously reported [44] [45] via incubation of biofilm with propidium iodide solution $(0.05 \mathrm{mg} / \mathrm{mL})$ at $37{ }^{\circ} \mathrm{C}$ for 24 $\mathrm{h}$ and detection of specific fluorescence at $620 \mathrm{~nm}$ after a thorough washing step with Milli-Q water. DMSO 1\% was used as a control. Experiments were performed in triplicate. Graphical illustrations of the results represent the mean values and error bars denote the standard deviation.

\subsection{Antibacterial activity assay}

Determination of growth inhibitory effects and minimum inhibitory concentrations (MICs) for the multifunctional DPI formulations and the antibiotics were performed as described in literature [46] [47]. Briefly, MIC values against P. aeruginosa PA14 were determined in 96-well plates (Sarstedt, Nümbrecht, Germany). As bacteria start $\mathrm{OD}_{600}, 0.03$ was used in a total volume of $200 \mu \mathrm{L}$ in LB medium containing the multifunctional DPI formulations/antibiotics dissolved in water or DMSO (maximal DMSO concentration in the experiments was 1\%). Six concentrations of the antibiotics (in duplicate) were prepared by two-fold serial dilution starting from $0.1-0.3 \mu \mathrm{g} / \mathrm{mL}$ according to their concentration in the multifunctional DPI formulations. The ODs were measured using a PHERAstar Microplate reader (BMG Labtech, Ortenberg, Germany) after inoculation and incubation for $18 \mathrm{~h}$ at $37^{\circ} \mathrm{C}$ with $200 \mathrm{rpm}$. Given MIC values are means of two independent determinations and defined as the lowest concentration of compound that reduced $\mathrm{OD}_{600}$ by $\geq 95 \%$. Percent inhibition of bacterial growth was calculated for azithromycin, tobramycin, and the corresponding multifunctional DPI formulations, where no complete inhibition of bacterial growth was observed at the highest concentration $(0.3$ $\mu \mathrm{g} / \mathrm{mL})$

\subsection{Statistical analysis}

All statistical calculations were performed using GraphPad Prism 8.0.1 software. A one sample $t$-test was performed to calculate the statistical significance of the mean compared to the mean 
of the DMSO control (100\% biofilm or eDNA formation). An unpaired $t$-test with two-tailed $\mathrm{P}$ value $<0.05$ was used to compare significance between two groups.

\section{Results and discussion}

\subsection{Spray drying NAC with antibiotics}

Spray drying of drugs is an attractive approach to obtain micronized particles suitable for inhalation. Working with NAC as a functional matrix for spraying has not been achieved yet [48]. Spraying of pure NAC has resulted in strongly agglomerated particles (Fig. 1) and also the collection of the formulation was complicated due to the hard and sticky layer-like structure formed on the spray dryer's collector glass.

Mixing NAC with a compound offering an opposite charge was assumed to regulate hygroscopicity by salt formation. For complex formation, potentially charge-bearing antibiotics with different numbers of amino groups were chosen. To simultaneously represent different classes of antibiotics, ciprofloxacin (a fluoroquinolone), azithromycin (a macrolide antibiotic), and tobramycin (an aminoglycoside) were selected. For ciprofloxacin only an equimolar amount of NAC was necessary due to the fact that only the secondary amino group in the piperazine heterocycle is an amino group that can be ionized (the other two nitrogen atoms are in a vinylogous amide interaction with the keto groups inside the molecule, and for this reason, vinylogous amides are hard to protonate). To complex azithromycin, a molar ratio of 1:2 was chosen to address the two potential positive charges. For tobramycin, an already water-soluble antibiotic with five amino groups that are easily protonated, a molar ratio of 1:5 of tobramycin to NAC was chosen. These ratios were selected to achieve optimal concentrations for salt formation within the formulation. These ratios should also facilitate the formation of stable formulations of the spray-dried powder balancing the high hygroscopic potential of NAC. The ionization sites of all components are shown in Fig. 2. Salt formation could also improve the solubility necessary for spray drying from aqueous solution; e.g., dissolving azithromycin and NAC using a molar ratio of 1:2 indeed resulted in a clear aqueous solution (Fig. S1). Converting 
the antibiotics into a salt form would also increase their solubility at the deposition site and accordingly the efficacy of the treatment, as the local drug concentration will be increased [10, 49].

The difference between the $\mathrm{p} K_{\mathrm{a}}$ values of an acidic and a basic compound gives a general estimate of salt formation if $\Delta \mathrm{p} K_{\mathrm{a}}$ is above 2 or $3\left[\underline{50]}\right.$. The $\Delta \mathrm{p} K_{\mathrm{a}}$ (Azi\&NAC) $=8.61, \Delta \mathrm{p} K_{\mathrm{a}}$ $($ Tobra\&NAC $)=8.72$ and $\Delta \mathrm{p} K_{\mathrm{a}(\mathrm{Cipro} \& \mathrm{NAC})}=4.86$ strongly suggests possible salt formation. All these antibiotics and NAC formulations were successfully sprayed and available as DPI formulation. To counterbalance the hygroscopic properties of NAC, L-leucine was added to the formulations as it has previously been shown to shield hygroscopic dry powders from wetting and therefore early disintegration [51]. This effect can be explained by the lipophilic tert-butylic tail of Lleucine which strengthens the hydrophobic properties of formulations, prevents water to adsorb at the particle surface and to penetrate in the deeper layers of the particles [51]. All three formulations of antibiotic/NAC displayed similar handling properties with respect to collecting and storing. This implies low moisture content and a low tendency towards aggregation. As illustrated in Fig. 3, all formulations consisted of mostly spherical particles. Cipro/NAC and Azi/NAC formulations exhibited smoother surfaces than the Tobra/NAC formulation, which had a raisin-like appearance.

\subsection{Solid state characterization}

\subsubsection{Solid-state form}

The solid-state forms of the three spray-dried DPI formulations were determined with XRPD. This approach gives initial information about the degree of amorphousness (or otherwise) of the samples [드]. The diffractograms of the DPI formulations showed a halo pattern without peaks (Fig. 4a). This halo pattern is a characteristic property of amorphous solids and it is an indication that all the DPI formulations were amorphous after spray drying.

\subsubsection{Glass-transition temperature $\left(T_{g}\right)$}


The $T_{g}$ is another characteristic property of amorphous solids and indicates a change from the glassy state to the supercooled liquid (rubbery) state. The $T_{g}$ is a second order thermal event and usually determined as a sigmoidal step change in heat flow (or heat capacity) in mDSC thermograms $[\underline{32}, \underline{53}]$. The $T_{g} \mathrm{~s}$ of the neat amorphous starting materials, except for LEU, which could not be amorphized (thermograms not shown), and the DPI formulations (Fig. 4b) were determined and the results are shown in Table 2.

In Fig. 4b, a single sigmoidal step change in the reversing heat-flow thermogram can be observed for the DPI formulations. This is an indication that co-amorphous systems have been obtained [36]. For co-amorphous systems, their $T_{g}$ values are concentration-dependent and the values are usually between those of the pure starting materials [느, $\underline{54}]$. However, for Cipro/NAC, the experimental $T_{g}\left(93.3^{\circ} \mathrm{C}\right)$ was similar to that of neat amorphous ciprofloxacin $\left(90.5^{\circ} \mathrm{C}\right)$. This indicates that different amorphous phases (a Cipro-rich and a NAC-rich phase) are present and that Cipro/NAC does not form a co-amorphous system.

For Azi/NAC and Tobra/NAC that formed co-amorphous systems, their $T_{g} \mathrm{~s}$ were compared to theoretical values based on the Fox equation (contribution of LEU to the predicted $T_{g}$ was neglected as its concentration was low). The theoretical values (shown in Table 2) are significantly lower compared to the experimentally determined values. A positive deviation of the experimentally determined values from theoretical values indicates molecular interactions between the drug and the co-former, and from the $\mathrm{pKa}$ differences between the two drugs and $\mathrm{NAC}\left(\Delta \mathrm{p} K_{\mathrm{a}(\text { Azi\&NAC) }}=8.61, \Delta \mathrm{p} K_{\mathrm{a}(\text { Tobra\&NAC })}=8.72\right)$, the molecular interaction is very likely to be due to salt formation [므].

\subsection{In vitro aerodynamic properties}

The aerodynamic properties of particles are an important criterion for novel formulations for inhalation. Particles with a diameter bigger than $5 \mu \mathrm{m}$ are described to mainly deposit in the oropharynx and large conducting airways, whilst particles ranging from 1 to $5 \mu \mathrm{m}$ predominantly deposit in the small airways and alveoli [ㄷ5]. Thus, the aerodynamic properties 
of the DPI formulations were investigated using the Next Generation Impactor (NGI). The data obtained, such as the mass median aerodynamic diameter (MMAD), the geometric mean (GSD), and the fine particle fraction (FPF) are depicted in Table 3. All formulations showed a high FPF of at least $60 \%$ and comparable MMAD values ranging from 2.16 up to $2.63 \mu \mathrm{m}$. The multifunctional powder formulations thus exhibited appropriate aerodynamic properties for pulmonary application such as for chronic lung infections in CF. Other factors playing a role for the development of an optimal dry powder formulation (e.g., powder flowability and hygroscopicity) will be investigated in the future.

\subsection{Disintegration behavior of the multifunctional DPI formulations in humid} air

For powder formulations intended for inhalation, an appropriate disintegration rate of the matrix is crucial. Upon deposition into the lungs, a rapid disintegration of the final product in the available (low) amount of fluid is desired [드. The combination of the antibiotics with NAC already revealed a positive effect of the salt formation, as drugs with low solubility (azithromycin and ciprofloxacin) became more water-soluble. To investigate their dispersibility, the powder formulations were applied onto a filter membrane at $100 \% \mathrm{RH}$; then the membrane was placed on an agarose gel and stored at $37^{\circ} \mathrm{C}$. The fate of the particles on the membrane was visualized using SEM. As a control, spray-dried azithromycin alone without NAC was used. Spray drying of tobramycin and ciprofloxacin alone was not possible without the presence of NAC and could therefore not be used as controls. In comparison to spray-dried free azithromycin without NAC, the powder formulation containing Azi/NAC started to dissolve immediately $(\mathrm{t}=5 \mathrm{~min})$ after placing them on the agarose gel while being mounted on the nitrocellulose membrane (Fig. 5). The spray-dried pure azithromycin did not dissolve up to 30 min (Fig. 5). These results confirm that the presence of NAC in the multifunctional DPI formulation improved solubilization of the antibiotic based on the salification process [49]. In the case of Tobra/NAC and Cipro/NAC, the DPI formulations also showed a fast disintegration 
(Fig. S2). Moreover, we have noticed that cleaning the spray drier after the experiments for formulations containing NAC (and in contrast to spray-dried pure azithromycin without NAC) could easily be done only using pure water, further indicating improved solubility of the NAC/antibiotic complex formed.

\subsection{Effect of multifunctional DPI formulation on the rheological properties of mucus}

Mucus and especially the dense viscous mucus in CF reduces the permeability of drugs and drug carriers. Therefore, a mucolytic agent such as NAC is used to fluidize the mucus and thus enhance permeation [ $\underline{57}$. The viscosity of pulmonary horse mucus before and after applying the multifunctional formulations was measured, to assess NAC's influence on the rheological properties of mucus. Mucus was appropriately diluted with pure water to account for the dilution effect introduced by applying the dissolved DPI formulations and was taken as control. When pure NAC solution was added to mucus, a pronounced reduction in the viscosity from $60 \mathrm{~Pa}$ s to $18 \mathrm{~Pa}$ s (Fig. 6) was observed, due to NAC's ability to cleave disulfide bonds between mucins [27]. Adding the multifunctional powder formulations onto the mucus also led (within $5 \mathrm{~min}$ ) to a reduction in the viscosity of mucus from 60 to $19 \mathrm{~Pa}$. These results confirm the efficacy of NAC as mucolytic agent when incorporated in the DPI formulations (Fig. 6).

\subsection{Stability of spray-dried multifunctional DPI formulations}

The freshly prepared amorphous DPI formulations were stored at $65{ }^{\circ} \mathrm{C}$ for six weeks and at $125{ }^{\circ} \mathrm{C}$ for twenty minutes to investigate storage stability in the glassy and supercooled liquid form, respectively. The physical stability for Cipro/NAC, determined by XRPD, is shown in Fig. 7A. The diffractograms show complete recrystallization after storage under both storage conditions with clearly identifiable peaks belonging to either ciprofloxacin or LEU or both. SEM images before and after storage also showed differences in surface morphology of the particles, again indicating recrystallization (Fig. S3). 
The physical stability of the co-amorphous Azi/NAC and Tobra/NAC formulations is depicted in Fig. 7B, C. The amorphous halo is maintained, both, in the glassy or supercooled liquid form of the formulations. The peaks observed at 6.0 and $19.5^{\circ}(2 \theta)$, for formulations stored at 125 ${ }^{\circ} \mathrm{C}$, are characteristic peaks of LEU. The morphology, determined using SEM, of Azi/NAC and Tobra/NAC co-amorphous DPI formulations also did not change as a function of storage. In summary, the co-amorphous DPI formulations are physically stable under stress storage conditions and by extrapolation, will be stable at RT.

\subsection{In vitro evaluation of the effect of multifunctional DPI formulations against P. aeruginosa biofilm}

P. aeruginosa biofilm is a community of bacterial cells embedded in a mixture of biopolymers, e.g., polysaccharides, proteins, lipids, and extracellular DNA (eDNA) forming the biofilm matrix [58]. These extracellular polymeric substances have structural, nutritional, and protective functions in the biofilm. The eDNA component of the biofilm matrix plays an important role in biofilm formation, virulence as well as antibiotic resistance [59-61]. We studied the effect of the multifunctional DPI formulations on biofilm formation of the highly virulent clinical isolate $P$. aeruginosa PA14 using the crystal violet (CV) biofilm and eDNA assays [43-45]. The multifunctional DPI formulations containing different concentrations of the antibiotic were screened to determine the appropriate concentration that reveals the impact of the DPI formulations on biofilm, as at high concentration of antibiotic, potential effects can be concealed by the inhibition of bacterial growth. Neat antibiotics and NAC at the same concentration as in multifunctional DPI formulations were used as references. Results revealed that Azi/NAC formulation reduced the biofilm by $25 \%(\mathrm{p}<0.0001$ compared to control and azithromycin alone) at a concentration of $0.3 \mu \mathrm{g} / \mathrm{mL}$, while neither azithromycin nor NAC separately showed significant inhibition (Fig. 8). At $10 \mu \mathrm{g} / \mathrm{mL}$, the Azi/NAC formulation displayed $40 \%$ inhibition ( $\mathrm{p}<0.001$ compared to control) slightly less than azithromycin alone $(55 \%, \mathrm{p}<0.0001)$ (Fig. 8). This might be attributed to a difference in the rate of dissociation to 
the free base between azithromycin and the Azi/NAC salt in the formulation at this concentration [62]. No significant difference was observed between ciprofloxacin and the Cipro/NAC formulation. They exhibited about $65 \%$ inhibition $(\mathrm{p}<0.0001$ compared to control) at a concentration of $0.1 \mu \mathrm{g} / \mathrm{mL}$, and $88 \%$ suppression at $0.3 \mu \mathrm{g} / \mathrm{mL}(\mathrm{p}<0.0001$ compared to control) (Fig. 8). The equipotent effects of ciprofloxacin and Cipro/NAC formulation can be ascribed to the growth inhibitory effect of ciprofloxacin at concentrations of 0.1 and $0.3 \mu \mathrm{g} / \mathrm{mL}$, which are corresponding to 2- and 6-fold MIC values, respectively (Table S1). At $0.1 \mu \mathrm{g} / \mathrm{mL}$, no inhibition of biofilm was observed for tobramycin, NAC, and the corresponding formulation (Fig. 8). Interestingly, Tobra/NAC formulation showed 70\% reduction of biofilm $(\mathrm{p}<0.0001$ compared to control and $\mathrm{p}<0.001$ compared to tobramycin only) at a concentration of 0.3 $\mu \mathrm{g} / \mathrm{mL}$ versus $35 \%(\mathrm{p}<0.001)$ or no inhibition for each ingredient alone, respectively (Fig. 8). At $10 \mu \mathrm{g} / \mathrm{mL}$, both tobramycin and Tobra/NAC formulation exhibited almost full inhibition of the biofilm (95\%, p $<0.0001$ compared to control) (Fig. 8). The latter similar effects could be attributed to the high antibiotic concentration as mentioned above. It is noteworthy that NAC concentrations in this study range from $0.049 \mu \mathrm{g} / \mathrm{mL}$ to $17 \mu \mathrm{g} / \mathrm{mL}$ in Cipro/NAC $(0.1 \mu \mathrm{g} / \mathrm{mL})$ and Tobra/NAC (10 $\mu \mathrm{g} / \mathrm{mL})$ DPI formulations, respectively. These concentrations are much lower than the reported values for NAC $(0.5-80 \mathrm{mg})$ needed to inhibit the biofilm formation in $P$. aeruginosa in vitro $[27,29]$. This could explain the lack of activity for NAC alone and the substantial effect in combination with antibiotics against the biofilm. Nevertheless, the significant enhancement of activity for Azi/NAC and Tobra/NAC formulations at $0.3 \mu \mathrm{g} / \mathrm{mL}$ compared to those of the separate components indicates the potential advantages of the combinations. In addition, further optimization of the antibiotic/NAC ratio might be needed to augment the antibiofilm activity.

The inhibitory effects of the antibiotic/NAC formulations on eDNA were in line with those on the whole biofilm. Remarkably, the effect of NAC was more pronounced on the eDNA component alone (38 - 54\% inhibition, Fig. S4) compared to a rather slight activity in the whole 
biofilm assay at the tested concentrations. Interestingly, we observed a significant increase $(18-46 \%, \mathrm{p}<0.05$ compared to control) in the biofilm and eDNA formation for azithromycin at $0.3 \mu \mathrm{g} / \mathrm{mL}$ and tobramycin at $0.1 \mu \mathrm{g} / \mathrm{mL}$ (Fig. 8 and $\mathrm{S} 4$ ). It has been reported that this phenomenon occurs when antibiotics are present in concentrations below MIC levels $[\underline{63}, \underline{64}]$. On the other hand, we did not observe such induction for the DPI formulations having the same concentration of antibiotics. Taken together, these results demonstrate that the new antibiotic/NAC combinations in the formulation could have beneficial effects or at least maintain the antibiotic and NAC properties for biofilm inhibition.

\subsection{Effect of multifunctional DPI formulations on antibiotic susceptibility}

To investigate whether the interaction of NAC with the antibiotics would modulate their antibacterial activity, we tested the antibiotic/NAC formulations, the neat antibiotics, and NAC against $P$. aeruginosa PA14 using the bacterial growth-inhibition assay $[\underline{46}, \underline{47}]$. Pure NAC did not show any inhibition of $P$. aeruginosa PA14 growth in the concentration range of 0.049 to $0.52 \mu \mathrm{g} / \mathrm{mL}$ corresponding to those in the tested formulations. No significant difference was observed between the growth-inhibitory activities in the presence and absence of DPI formulations for azithromycin and tobramycin (Table S1). Susceptibility to ciprofloxacin in the formulation also did not change (MIC values: $0.05 \mu \mathrm{g} / \mathrm{mL}$ versus $0.06 \mu \mathrm{g} / \mathrm{mL}$ for the neat antibiotic). Altogether, the antibiotic/NAC combination in the DPI formulations did not show significant alteration of the antibacterial activities compared to the neat antibiotics and the MIC values against $P$. aeruginosa PA14 are in accordance with previous findings $[\underline{65}, \underline{66}]$.

\section{Conclusions}

Respirable multifunctional DPI formulations composed of antibiotics and NAC as matrix were successfully developed. Azi/NAC and Tobra/NAC formulations were found to be coamorphous salt formulations. Salt formation between the antibiotics an NAC allowed for improving the solubility of the antibiotics. Furthermore, it also enabled the successful formation of DPI formulations using spray drying. Physical stability experiments indicated that the 
formulations retained their amorphous form after storage under stress conditions. The shelfstability of these multifunctional DPI formulations was investigated with respect to their morphology and agglomeration behaviour, revealing stable DPI formulations for azithromycin/NAC and tobramycin/NAC over a range of nine months. The salt formation may also have contributed to a reduced hygroscopicity of the DPI formulations and a positive effect on the redispersibility of the dry powder formulations at $100 \% \mathrm{RH}$. In addition to these physicochemical aspects, the obtained multifunctional DPI formulations of antibiotic/NAC displayed suitable aerodynamic properties with fine particle fractions above $65 \%$. Besides promising deposition behavior, the application of NAC reduced mucus viscosity. Furthermore, the coformulated antibiotics allow a direct treatment of residing bacteria as the antibiotic/NAC DPI formulations improved or at least maintained both, antibiotic susceptibility and NAC inhibitory properties on $P$. aeruginosa PA14 biofilms. The combination of antibiotics and NAC, exploiting co-amorphous salt formation has allowed us to realize a novel multifunctional DPI formulation and this knowledge may provide the basis to formulate a variety of drug combinations for inhalation as dry powders.

\section{Acknowledgements}

The authors thank Simone Amann and Jeannine Jung for technical assistance in the biofilm and antibacterial activity assays.

AKHH acknowledges funding from the Helmholtz Association's Initiative and Networking Fund and the ERC (Starting Grant 757913. 


\section{References}

[1] M. Welsh, B. Ramsey, F. Accurso, G. Cutting, C. Scriver, A. Beaudet, W. Sly, D. Valle, The metabolic and molecular basis of inherited disease, Scriver, CR, (2001) 5121-5189.

[2] S. Moreau-Marquis, B.A. Stanton, G.A. O'Toole, Pseudomonas aeruginosa biofilm formation in the cystic fibrosis airway, Pulm Pharmacol Ther., 21 (2008) 595-599. doi: 510.1016/j.pupt.2007.1012.1001. Epub 2008 Jan 1029.

[3] B. Cystic Fibrosis Foundation, MD, USA (2010), Cystic fibrosis foundation patient registry 2009 annual data report.

[4] J.B. Lyczak, C.L. Cannon, G.B. Pier, Lung infections associated with cystic fibrosis, Clin Microbiol Rev, 15 (2002) 194-222.

[5] P.J. Mogayzel, Jr., E.T. Naureckas, K.A. Robinson, G. Mueller, D. Hadjiliadis, J.B. Hoag, L. Lubsch, L. Hazle, K. Sabadosa, B. Marshall, Cystic fibrosis pulmonary guidelines. Chronic medications for maintenance of lung health, Am J Respir Crit Care Med, 187 (2013) 680-689.

[6] P.A. Flume, B.P. O'sullivan, K.A. Robinson, C.H. Goss, P.J. Mogayzel Jr, D.B. Willey-Courand, J. Bujan, J. Finder, M. Lester, L. Quittell, Cystic fibrosis pulmonary guidelines: chronic medications for maintenance of lung health, American journal of respiratory and critical care medicine, 176 (2007) 957969.

[7] P. Agent, H. Parrott, Inhaled therapy in cystic fibrosis: agents, devices and regimens, Breathe, 11 (2015) 110.

[8] M.D. Parkins, R. Somayaji, V.J. Waters, Epidemiology, biology, and impact of clonal Pseudomonas aeruginosa infections in cystic fibrosis, Clinical microbiology reviews, 31 (2018) e00019-00018.

[9] S.W. Yapa, J. Li, K. Patel, J.W. Wilson, M.J. Dooley, J. George, D. Clark, S. Poole, E. Williams, C.J. Porter, Pulmonary and systemic pharmacokinetics of inhaled and intravenous colistin methanesulfonate in cystic fibrosis patients: targeting advantage of inhalational administration, Antimicrobial agents and chemotherapy, 58 (2014) 2570-2579.

[10] Y. Akdag Cayli, S. Sahin, F. Buttini, A.G. Balducci, S. Montanari, I. Vural, L. Oner, Dry powders for the inhalation of ciprofloxacin or levofloxacin combined with a mucolytic agent for cystic fibrosis patients, Drug development and industrial pharmacy, 43 (2017) 1378-1389.

[11] S. Smith, N.J. Rowbotham, E. Charbek, Inhaled antibiotics for pulmonary exacerbations in cystic fibrosis, Cochrane Database of Systematic Reviews, (2018).

[12] W.D. Smith, E. Bardin, L. Cameron, C.L. Edmondson, K.V. Farrant, I. Martin, R.A. Murphy, O. Soren, A.R. Turnbull, N. Wierre-Gore, Current and future therapies for Pseudomonas aeruginosa infection in patients with cystic fibrosis, FEMS microbiology letters, 364 (2017).

[13] P. Tappenden, S. Harnan, L. Uttley, M. Mildred, C. Carroll, A. Cantrell, Colistimethate sodium powder and tobramycin powder for inhalation for the treatment of chronic Pseudomonas aeruginosa lung infection in cystic fibrosis: systematic review and economic model, Health Technol Assess, 17 (2013) 1-181.

[14] F. Pierart, [TOBI Podhaler for treating chronic Pseudomonas aeruginosa infection in cystic fibrosis patients], Rev Med Liege, 68 (2013) 486-488.

[15] G.Z. Retsch-Bogart, A.L. Quittner, R.L. Gibson, C.M. Oermann, K.S. McCoy, A.B. Montgomery, P.J. Cooper, Efficacy and safety of inhaled aztreonam lysine for airway pseudomonas in cystic fibrosis, Chest, 135 (2009) 1223-1232.

[16] S. Smith, N.J. Rowbotham, K.H. Regan, Inhaled anti-pseudomonal antibiotics for long-term therapy in cystic fibrosis, Cochrane Database of Systematic Reviews, (2018).

[17] C. Moon, H.D.C. Smyth, A.B. Watts, R.O. Williams, 3rd, Delivery Technologies for Orally Inhaled Products: an Update, AAPS PharmSciTech., 20 (2019) 117. doi: 110.1208/s12249-12019-11314-12242. [18] T.A. Standaert, G.L. Morlin, J. Williams-Warren, P. Joy, M.S. Pepe, A. Weber, B.W. Ramsey, Effects of repetitive use and cleaning techniques of disposable jet nebulizers on aerosol generation, Chest, 114 (1998) 577-586.

[19] K.L. Barnes, R. Clifford, S.T. Holgate, D. Murphy, P. Comber, E. Bell, Bacterial contamination of home nebuliser, British medical journal (Clinical research ed.), 295 (1987) 812. 
[20] S. Vassal, R. Taamma, N. Marty, A. Sardet, P. d'Athis, F. Brémont, M. Dalphin, P. Plésiat, G. Rault, J. Thubert, Microbiologic contamination study of nebulizers after aerosol therapy in patients with cystic fibrosis, American journal of infection control, 28 (2000) 347-351.

[21] W.A. Kradjan, S. Lakshminarayan, Efficiency of air compressor-driven nebulizers, Chest, 87 (1985) 512-516.

[22] D.E. Geller, M. Rosenfeld, D.A. Waltz, R.W. Wilmott, Efficiency of pulmonary administration of tobramycin solution for inhalation in cystic fibrosis using an improved drug delivery system, Chest Journal, 123 (2003) 28-36.

[23] E. Köhler, V. Sollich, R. Schuster-Wonka, J. Hühnerbein, Lung deposition in cystic fibrosis patients using an ultrasonic or a jet nebulizer, Journal of aerosol medicine, 16 (2003) 37-46.

[24] O.N. McCallion, K.M. Taylor, M. Thomas, A.J. Taylor, Nebulization of fluids of different physicochemical properties with air-jet and ultrasonic nebulizers, Pharmaceutical research, 12 (1995) 1682-1688.

[25] M. Hoppentocht, P. Hagedoorn, H. Frijlink, A. De Boer, Technological and practical challenges of dry powder inhalers and formulations, Advanced drug delivery reviews, 75 (2014) 18-31.

[26] G. Pilcer, J. Goole, B. Van Gansbeke, D. Blocklet, C. Knoop, F. Vanderbist, K. Amighi, Pharmacoscintigraphic and pharmacokinetic evaluation of tobramycin DPI formulations in cystic fibrosis patients, European journal of pharmaceutics and biopharmaceutics, 68 (2008) 413-421.

[27] T. Zhao, Y. Liu, N-acetylcysteine inhibit biofilms produced by Pseudomonas aeruginosa, BMC microbiology, 10 (2010) 140.

[28] C. Conrad, J. Lymp, V. Thompson, C. Dunn, Z. Davies, B. Chatfield, D. Nichols, J. Clancy, R. Vender, M. Egan, Long-term treatment with oral $\mathrm{N}$-acetylcysteine: affects lung function but not sputum inflammation in cystic fibrosis subjects. A phase II randomized placebo-controlled trial, Journal of Cystic Fibrosis, 14 (2015) 219-227.

[29] F. Blasi, C. Page, G.M. Rossolini, L. Pallecchi, M.G. Matera, P. Rogliani, M. Cazzola, The effect of $\mathrm{N}$-acetylcysteine on biofilms: Implications for the treatment of respiratory tract infections, Respiratory medicine, 117 (2016) 190-197.

[30] S. Ferrari, C. Kitson, R. Farley, R. Steel, C. Marriott, D. Parkins, M. Scarpa, B. Wainwright, M. Evans, W. Colledge, Mucus altering agents as adjuncts for nonviral gene transfer to airway epithelium, Gene therapy, 8 (2001) 1380.

[31] A. Henning, M. Schneider, M. Bur, F. Blank, P. Gehr, C.M. Lehr, Embryonic chicken trachea as a new in vitro model for the investigation of mucociliary particle clearance in the airways, AAPS Pharm Sci Tech, 9 (2008) 521-527.

[32] Thomas Rades, Keith C. Gordon, Kirsten Graeser, A. Hassan, Molecular Structure, Properties, and States of Matter, in: L.A. Felton (Ed.) Remington: The Science and Practice of Pharmacy, Pharmaceutical Press, London, United Kingdom, 2013, pp. 117-206.

[33] E.O. Kissi, H. Grohganz, K. Lobmann, M.T. Ruggiero, J.A. Zeitler, T. Rades, Glass-Transition Temperature of the beta-Relaxation as the Major Predictive Parameter for Recrystallization of Neat Amorphous Drugs, J. Phys. Chem. B, 122 (2018) 2803-2808.

[34] G. Van den Mooter, The use of amorphous solid dispersions: A formulation strategy to overcome poor solubility and dissolution rate, Drug Discovery Today: Technologies, 9 (2012) e79-e85.

[35] R. Laitinen, P.A. Priemel, S. Surwase, K. Graeser, C.J. Strachan, H. Grohganz, T. Rades, Theoretical Considerations in Developing Amorphous Solid Dispersions, in: N. Shah, H. Sandhu, D.S. Choi, H. Chokshi, A.W. Malick (Eds.) Amorphous Solid Dispersions: Theory and Practice, Springer New York, New York, NY, 2014, pp. 35-90.

[36] S.J. Dengale, H. Grohganz, T. Rades, K. Löbmann, Recent advances in co-amorphous drug formulations, Advanced Drug Delivery Reviews, 100 (2016) 116-125.

[37] K. Löbmann, H. Grohganz, R. Laitinen, C. Strachan, T. Rades, Amino acids as co-amorphous stabilizers for poorly water soluble drugs - Part 1: Preparation, stability and dissolution enhancement, European Journal of Pharmaceutics and Biopharmaceutics, 85 (2013) 873-881. 
[38] E.O. Kissi, G. Kasten, K. Lobmann, T. Rades, H. Grohganz, The Role of Glass Transition Temperatures in Coamorphous Drug-Amino Acid Formulations, Mol Pharm, 15 (2018) 4247-4256.

[39] G. Kasten, K. Nouri, H. Grohganz, T. Rades, K. Löbmann, Performance comparison between crystalline and co-amorphous salts of indomethacin-lysine, International Journal of Pharmaceutics, 533 (2017) 138-144.

[40] D.S. Wishart, C. Knox, A.C. Guo, S. Shrivastava, M. Hassanali, P. Stothard, Z. Chang, J. Woolsey, DrugBank: a comprehensive resource for in silico drug discovery and exploration, Nucleic Acids Res., 34 (2006) D668-672. doi: 610.1093/nar/gkj1067.

[41] N.R. Rabbani, P.C. Seville, The influence of formulation components on the aerosolisation properties of spray-dried powders, J Control Release., 110 (2005) 130-140. doi: 110.1016/j.jconrel.2005.1009.1004. Epub 2005 Oct 1013.

[42] J.G. Fox, Influence of diluent and of copolymer composition on the glass temperature of a polymer system, Bull. Am. Phys. SOC., I ( 1956).

[43] R. Frei, A.S. Breitbach, H.E. Blackwell, 2-Aminobenzimidazole Derivatives Strongly Inhibit and Disperse Pseudomonas aeruginosa Biofilms, Angewandte Chemie International Edition, 51 (2012) 5226 5229.

[44] A. Thomann, A.G. de Mello Martins, C. Brengel, M. Empting, R.W. Hartmann, Application of dual inhibition concept within looped autoregulatory systems toward antivirulence agents against Pseudomonas aeruginosa infections, ACS chemical biology, 11 (2016) 1279-1286.

[45] M. Allesen-Holm, K.B. Barken, L. Yang, M. Klausen, J.S. Webb, S. Kjelleberg, S. Molin, M. Givskov, T. Tolker-Nielsen, A characterization of DNA release in Pseudomonas aeruginosa cultures and biofilms, Molecular microbiology, 59 (2006) 1114-1128.

[46] W.A. Elgaher, M. Fruth, M. Groh, J. Haupenthal, R.W. Hartmann, Expanding the scaffold for bacterial RNA polymerase inhibitors: design, synthesis and structure-activity relationships of ureido-heterocycliccarboxylic acids, RSC Advances, 4 (2014) 2177-2194.

[47] W. Zhu, J. Haupenthal, M. Groh, M. Fountain, R.W. Hartmann, New insights into the bacterial RNA polymerase inhibitor CBR703 as a starting point for optimization as an anti-infective agent, Antimicrobial agents and chemotherapy, 58 (2014) 4242-4245.

[48] M. Odziomek, T.R. Sosnowski, L. Gradoń, Conception, preparation and properties of functional carrier particles for pulmonary drug delivery, International journal of pharmaceutics, 433 (2012) 51-59.

[49] M.D. Manniello, P. Del Gaudio, R.P. Aquino, P. Russo, Clarithromycin and N-acetylcysteine co-spraydried powders for pulmonary drug delivery: A focus on drug solubility, International journal of pharmaceutics, 533 (2017) 463-469.

[50] P.H. Stahl, C.G.J.C.I. Wermuth, Handbook of pharmaceutical salts: properties, selection and use, 24 (2002) 21.

[51] L. Li, S. Sun, T. Parumasivam, J.A. Denman, T. Gengenbach, P. Tang, S. Mao, H.K. Chan, L-Leucine as an excipient against moisture on in vitro aerosolization performances of highly hygroscopic spray-dried powders, Eur J Pharm Biopharm, 102 (2016) 132-141.

[52] G. Kasten, H. Grohganz, T. Rades, K. Lobmann, Development of a screening method for coamorphous formulations of drugs and amino acids, Eur J Pharm Sci, (2016).

[53] S. Qi, Thermal Analysis of Pharmaceuticals, in: A. Müllertz, Y. Perrie, T. Rades (Eds.) Analytical Techniques in the Pharmaceutical Sciences, Advances in Delivery Science and Technology, New York, USA, 2016.

[54] M. Gordon, J.S. Taylor, Ideal copolymers and the second-order transitions of synthetic rubbers. i. non-crystalline copolymers, Journal of Applied Chemistry, 2 (1952) 493-500.

[55] N. Labiris, M. Dolovich, Pulmonary drug delivery. Part I: physiological factors affecting therapeutic effectiveness of aerosolized medications, British journal of clinical pharmacology, 56 (2003) 588-599.

[56] A. Torge, P. Grützmacher, F. Mücklich, M. Schneider, The influence of mannitol on morphology and disintegration of spray-dried nano-embedded microparticles, Europ J Pharm Sci, 104 (2017) 171-179.

[57] S.K. Lai, Y.-Y. Wang, D. Wirtz, J. Hanes, Micro-and macrorheology of mucus, Advanced drug delivery reviews, 61 (2009) 86-100. 
[58] H.-C. Flemming, J. Wingender, The biofilm matrix, Nature Reviews Microbiology, 8 (2010) 623.

[59] C.B. Whitchurch, T. Tolker-Nielsen, P.C. Ragas, J.S. Mattick, Extracellular DNA required for bacterial biofilm formation, Science, 295 (2002) 1487-1487.

[60] E.S. Gloag, L. Turnbull, A. Huang, P. Vallotton, H. Wang, L.M. Nolan, L. Mililli, C. Hunt, J. Lu, S.R. Osvath, Self-organization of bacterial biofilms is facilitated by extracellular DNA, Proceedings of the National Academy of Sciences, 110 (2013) 11541-11546.

[61] H. Mulcahy, L. Charron-Mazenod, S. Lewenza, Extracellular DNA chelates cations and induces antibiotic resistance in Pseudomonas aeruginosa biofilms, PLoS pathogens, 4 (2008) e1000213.

[62] A.T.M. Serajuddin, Salt formation to improve drug solubility, Advanced drug delivery reviews, 59 (2007) 603-616.

[63] J.B. Kaplan, Antibiotic-induced biofilm formation, Int J Artif Organs, 34 (2011) 737-751.

[64] J.F. Linares, I. Gustafsson, F. Baquero, J.L. Martinez, Antibiotics as intermicrobial signaling agents instead of weapons, Proceedings of the National Academy of Sciences, 103 (2006) 19484.

[65] J. Rodríguez-Beltrán, G. Cabot, E.Y. Valencia, C. Costas, G. Bou, A. Oliver, J. Blázquez, Nacetylcysteine selectively antagonizes the activity of imipenem in Pseudomonas aeruginosa by an OprDmediated mechanism, Antimicrobial agents and chemotherapy, 59 (2015) 3246-3251.

[66] G. Landini, T. Di Maggio, F. Sergio, J.-D. Docquier, G.M. Rossolini, L. Pallecchi, Effect of high Nacetylcysteine concentrations on antibiotic activity against a large collection of respiratory pathogens, Antimicrobial agents and chemotherapy, 60 (2016) 7513-7517. 


\section{Table Headings}

Table 1: Amount of NAC and antibiotic in the spray drying solution with the needed percentage of Lleucine.

Table 2: Glass transition temperatures $\left(\mathrm{T}_{\mathrm{g}} \mathrm{s}\right)$ of the neat amorphous starting materials and the multifunctional DPI formulations.

Table 3: Results of the NGI evaluation of the DPI formulations. 


\section{$\underline{\text { Figure Captions }}$}

Fig. 1: SEM micrograph of spray-dried pure NAC.

Fig. 2: Ionization site of antibiotics and NAC for the multifunctional DPI formulations.

Fig. 3: SEM micrographs of multifunctional DPI formulations. Azi/NAC (A), Cipro/NAC (B), Tobra/NAC (C).

Fig. 4: a) Diffractograms and b) thermograms (mDSC) of freshly prepared DPI formulations. Arrows in the thermograms show the sigmoidal step change in the reversing heat flow signal, indicating the glass transition temperature.

Fig. 5: SEM micrographs of the DPI formulation deposited on top of a nitrocellulose membrane. (A) Spray-dried azithromycin without NAC and (B) DPI formulation Azi/NAC at 5 min after being placed on top of agarose pads up to $30 \mathrm{~min}$.

Fig. 6: Effect of multifunctional DPI formulations containing NAC on the viscosity of mucus.

Fig. 7: Diffractograms of stored antibiotic/NAC samples. (A) Cipro/NAC samples showing recrystallization of ciprofloxacin (red arrows) and LEU (green arrow). A combined diffractogram of crystalline NAC, LEU and ciprofloxacin is shown for comparison. (B) Diffractogram of the coamorphous Azi/NAC and (C) Tobra/NAC samples after storage at $65^{\circ} \mathrm{C}$ for 6 weeks and $125^{\circ} \mathrm{C}$ for 20 min. The diffractogram of the crystalline LEU is shown for comparison in both diagrams.

Fig. 8: Effects of the multifunctional DPI formulations at different concentrations on biofilm formation in P. aeruginosa PA14. Neat antibiotics and NAC at the same concentrations as in the multifunctional DPI formulations were used as references. ns, not significant; $* \mathrm{p}<0.05 ; * * * \mathrm{p}<0.001$; and $* * * * \mathrm{p}$ $<0.0001$ indicate a significant difference $(t$-test) compared to control. 
Table 1: Amount of NAC and antibiotic in the spray drying solution with the needed percentage of L-leucine.

\begin{tabular}{|l|l|l|l|}
\hline Formulation & NAC [w\%] & Antibiotic [w\%] & L-Leucine [w\%] \\
\hline Azi/NAC & 28.83 & 66.17 & 5 \\
\hline Cipro/NAC & 29.7 & 60.3 & 10 \\
\hline Tobra/NAC & 57.22 & 32.78 & 10 \\
\hline
\end{tabular}

Table 2: The $T_{g}$ s of the neat amorphous starting materials and the multifunctional DPI formulations.

\begin{tabular}{c|cc}
\hline Sample Name & Experimental & Predicted Tg based \\
& $\boldsymbol{T}_{\boldsymbol{g}}$ & on Fox equation \\
Azi/NAC & $99.0 \pm 0.9$ & 66 \\
Azithromycin (QC) & $108.3 \pm 0.5$ & - \\
Tobra/NAC & $107.9 \pm 0.7$ & 38 \\
Tobramycin (QC) & $135.5 \pm 0.1$ & - \\
Cipro/NAC & $93.3 \pm 0.4$ & 50 \\
Ciprofloxacin (BM) & $90.5 \pm 0.1$ & - \\
N-acetyl-cysteine (QC) & $6.9 \pm 1.9$ & - \\
\hline
\end{tabular}

- Amorphous N-acetyl-cysteine, tobramycin and azithromycin were prepared via quench cooling (QC)

- $\quad$ Ciprofloxacin was made amorphous prepared by ball milling (BM) 
Table 3: Results of the NGI evaluation of the DPI formulations.

\begin{tabular}{|l|l|l|l|}
\hline & Cipro/NAC & Tobra/NAC & Azi/NAC \\
\hline MMAD $[\boldsymbol{\mu m}]$ & $2.40( \pm 0.02)$ & $2.16( \pm 0.33)$ & $2.63( \pm 0.03)$ \\
\hline GSD & $1.88( \pm 0.008)$ & $1.53( \pm 0.06)$ & $1.64( \pm 0.13)$ \\
\hline FPF [\%] & $61.60( \pm 5.23)$ & $97.52( \pm 15.36)$ & $67.40( \pm 9.41)$ \\
\hline
\end{tabular}

SD is provided in brackets 


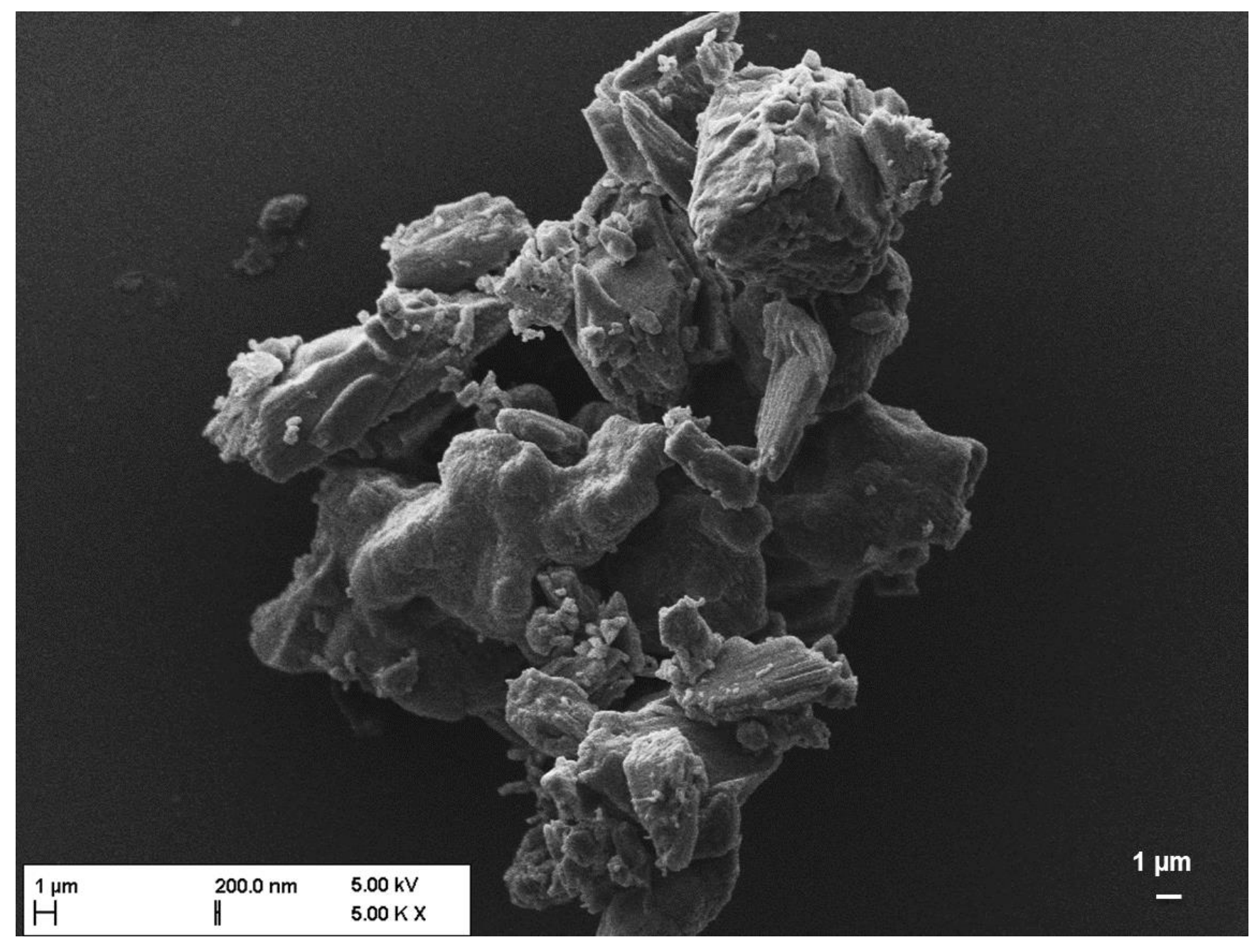

Fig. 1: SEM micrograph of spray-dried pure NAC. 
Carboxylic acid group

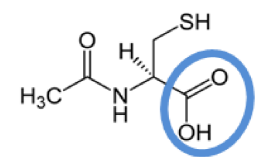

N-Acetylcysteine

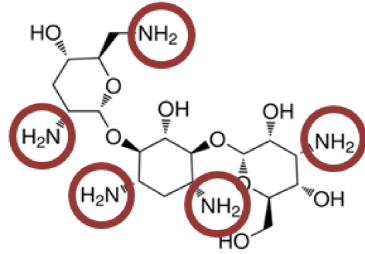

Tobramycin

Basic amino group

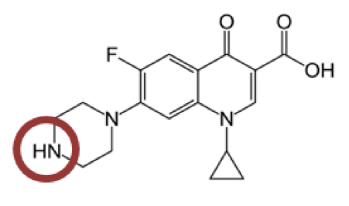

Ciprofloxacin

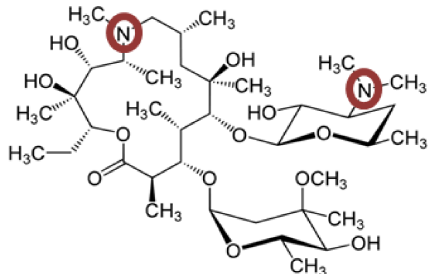

Azithromycin

Fig. 2: Ionization site of antibiotics and NAC for the multifunctional DPI formulations. 

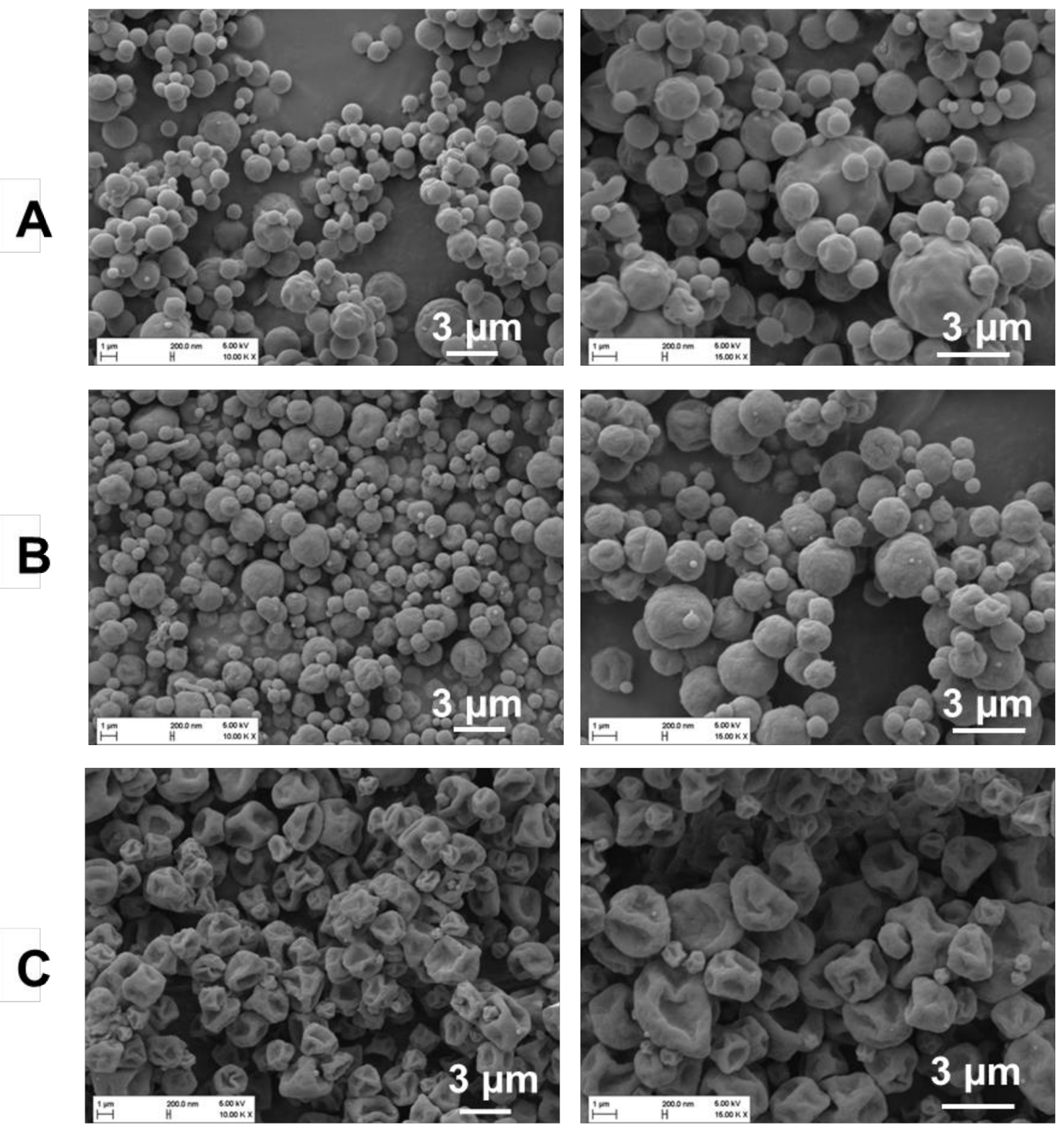

Fig. 3: SEM micrographs of multifunctional DPI formulations. Azi/NAC (A), Cipro/NAC (B), Tobra/NAC (C). 

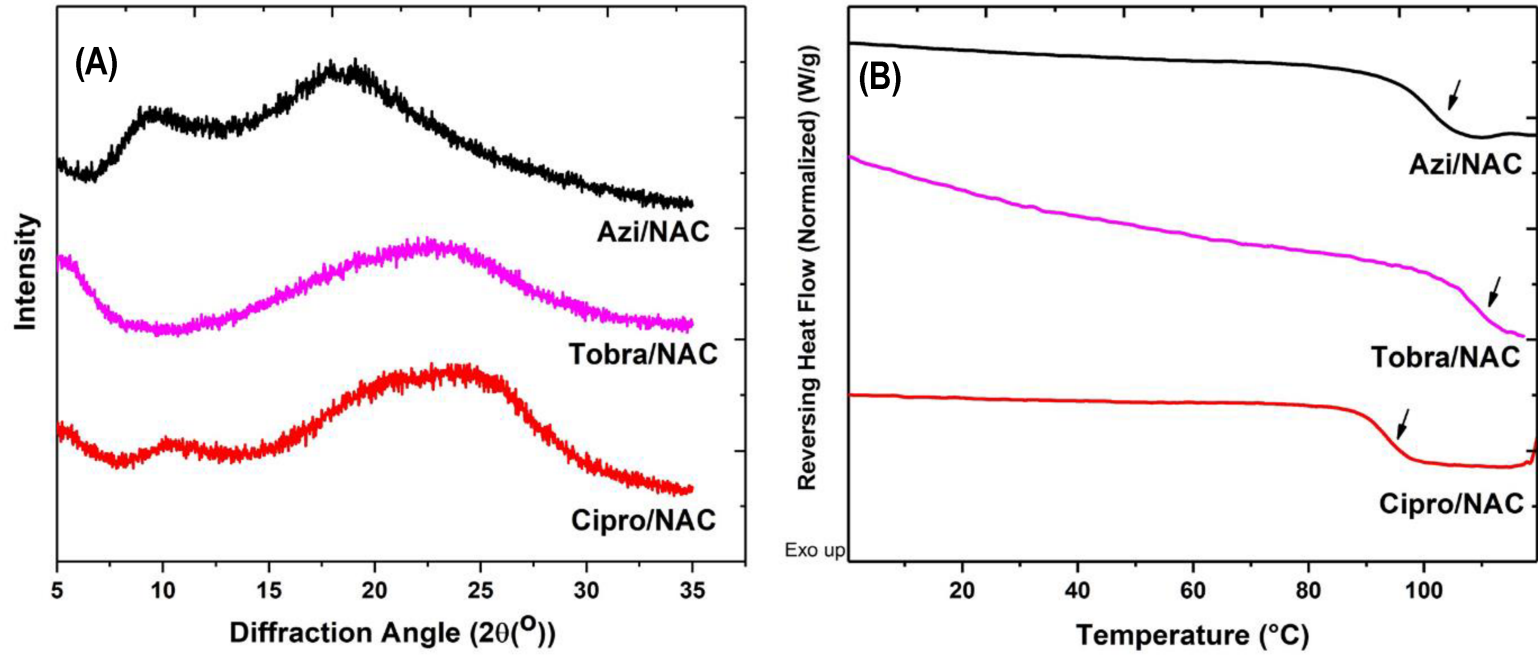

Fig. 4: (A) Diffractograms and (B) thermograms (mDSC) of freshly prepared DPI formulations. Arrows in the thermograms show the sigmoidal step change in the reversing heat flow signal, indicating the glass transition temperature. 
Spray-dried azithromycin without NAC

A
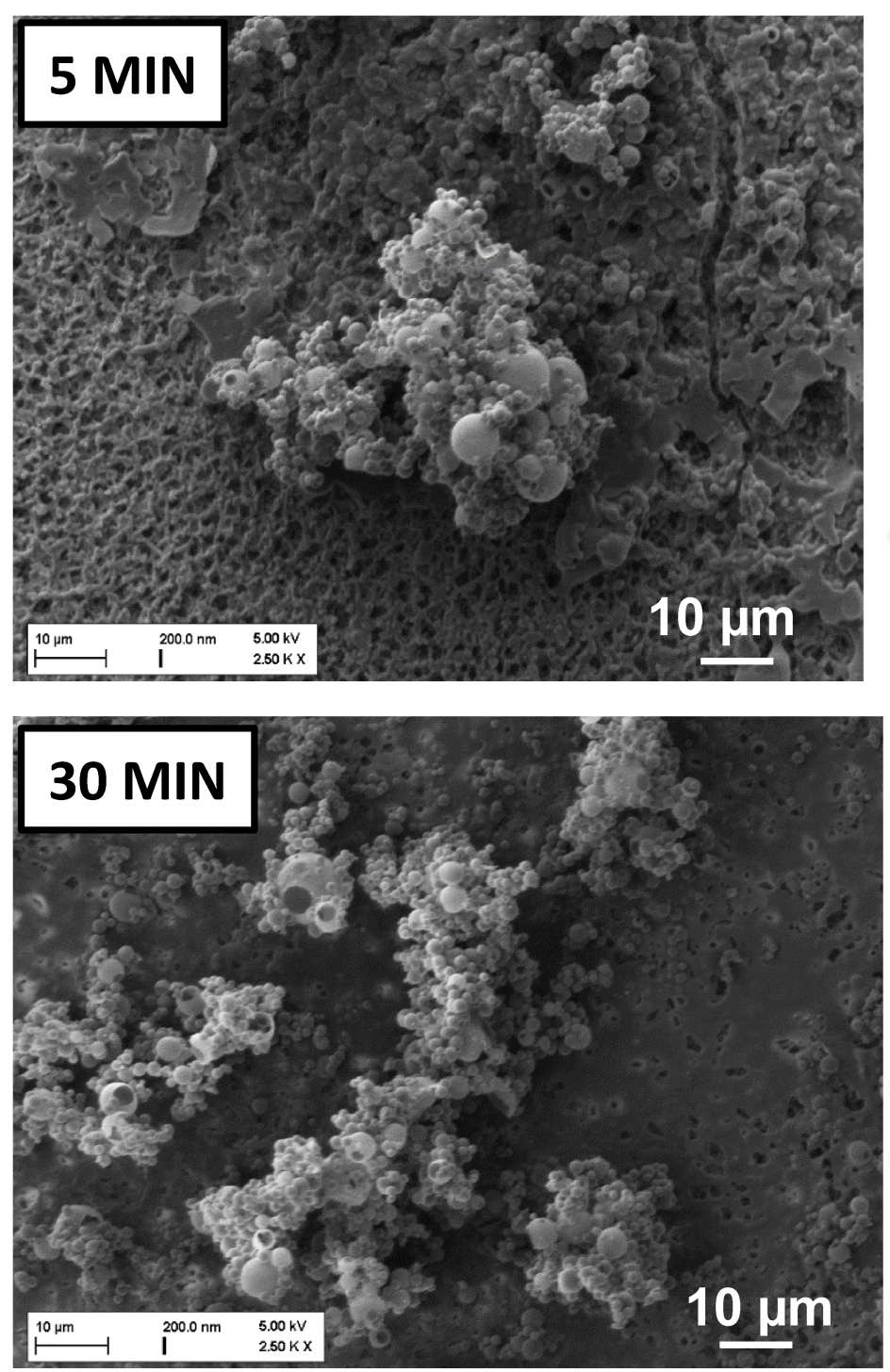

Spray-dried azithromycin with NAC

B
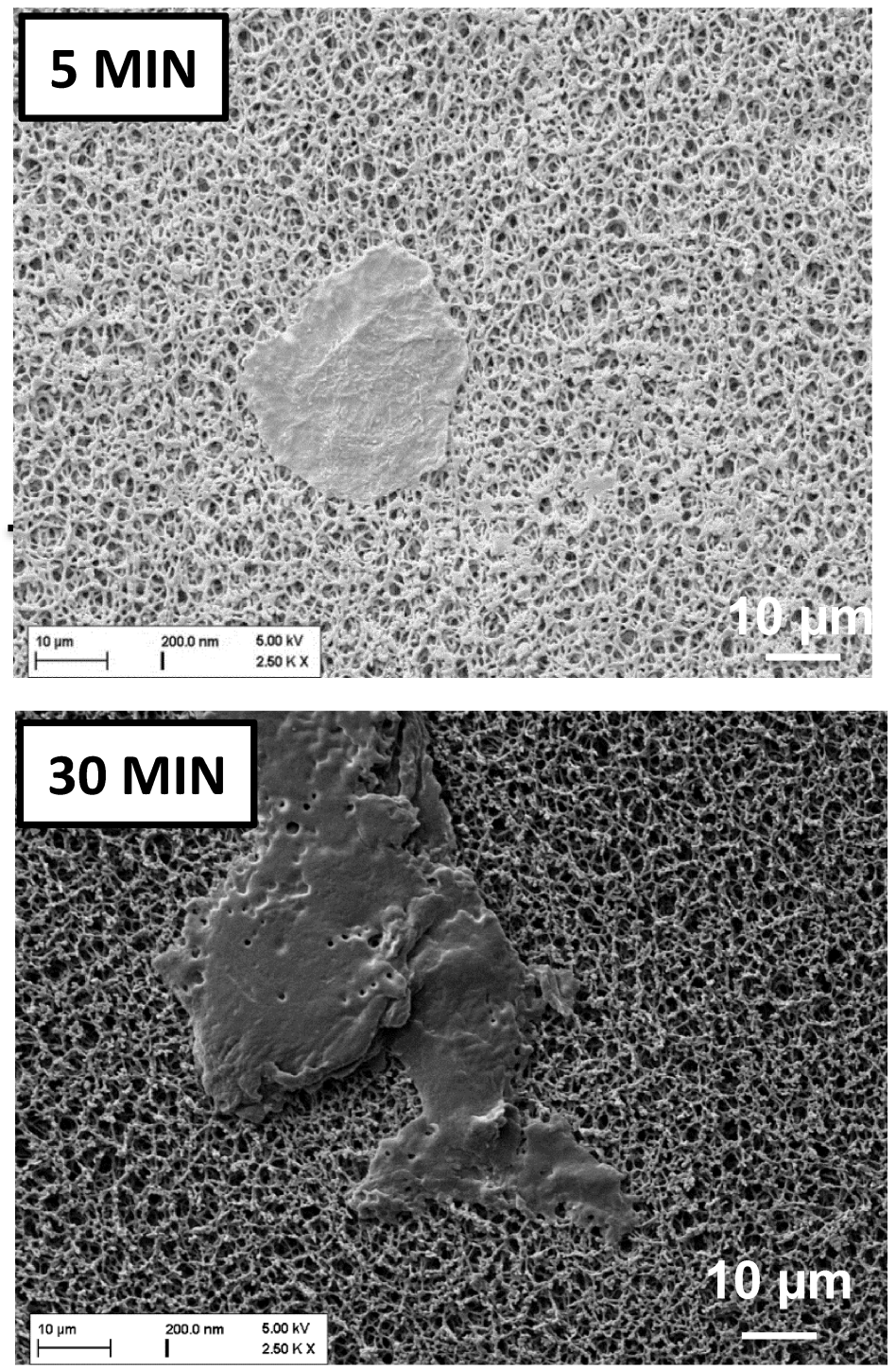

Fig. 5: SEM micrographs of the DPI formulation deposited on top of a nitrocellulose membrane. (A) Spray-dried azithromycin without NAC (B) DPI formulation Azi/NAC at $5 \mathrm{~min}$ after being placed on top of agarose pads up to $30 \mathrm{~min}$. 


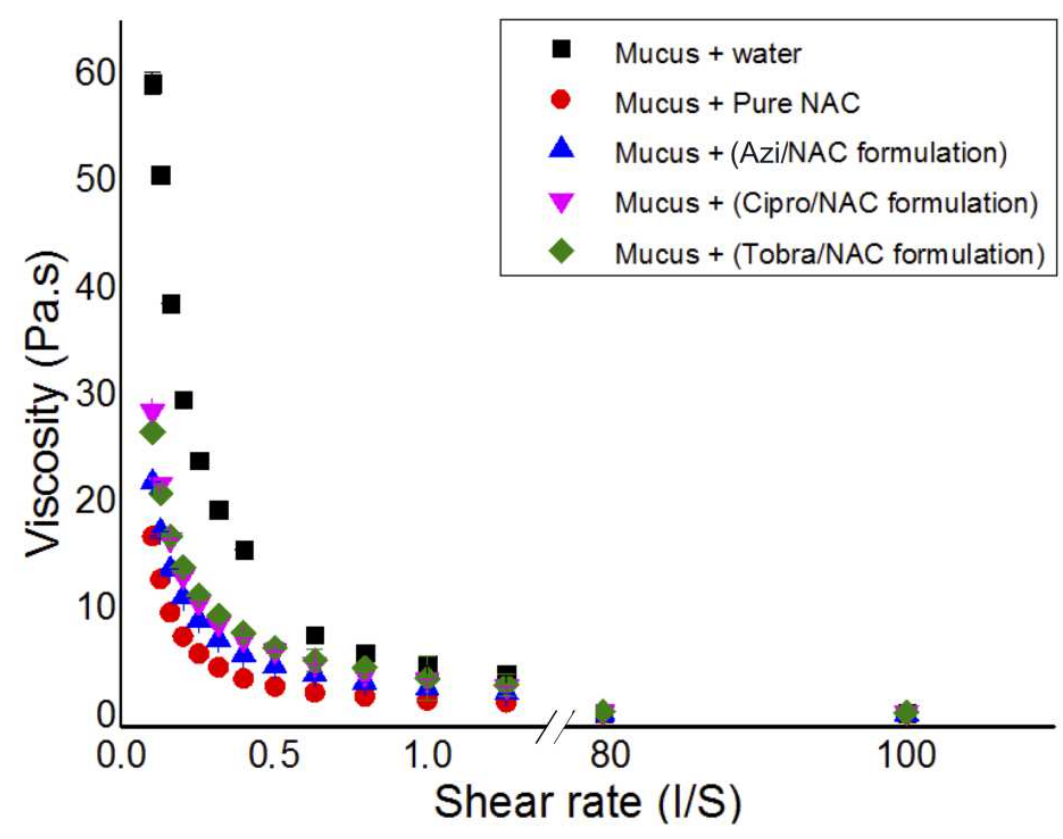

Fig. 6: Effect of multifunctional DPI formulations containing NAC on the viscosity of mucus. 

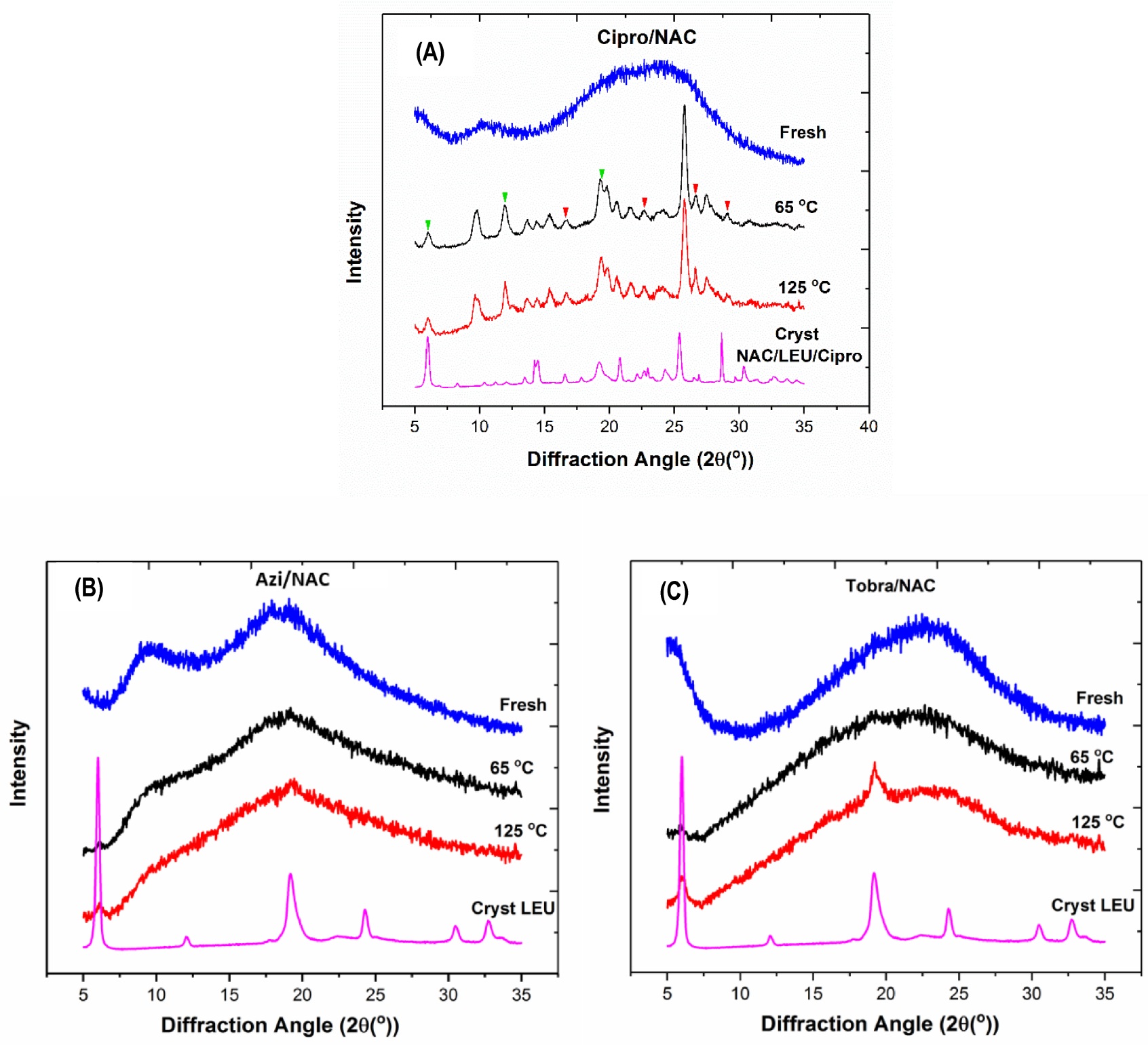

Fig. 7: Diffractograms of stored antibiotic/NAC samples. (A) Cipro/NAC samples showing recrystallization of ciprofloxacin (red arrows) and LEU (green arrow). A combined diffractogram of crystalline NAC, LEU and ciprofloxacin is shown for comparison. (B) Diffractogram of the co-amorphous Azi/NAC and (C) Tobra/NAC samples after storage at $65^{\circ} \mathrm{C}$ for 6 weeks and $125^{\circ} \mathrm{C}$ for $20 \mathrm{~min}$. The diffractogram of the crystalline LEU is shown for comparison in (B) and (C). 


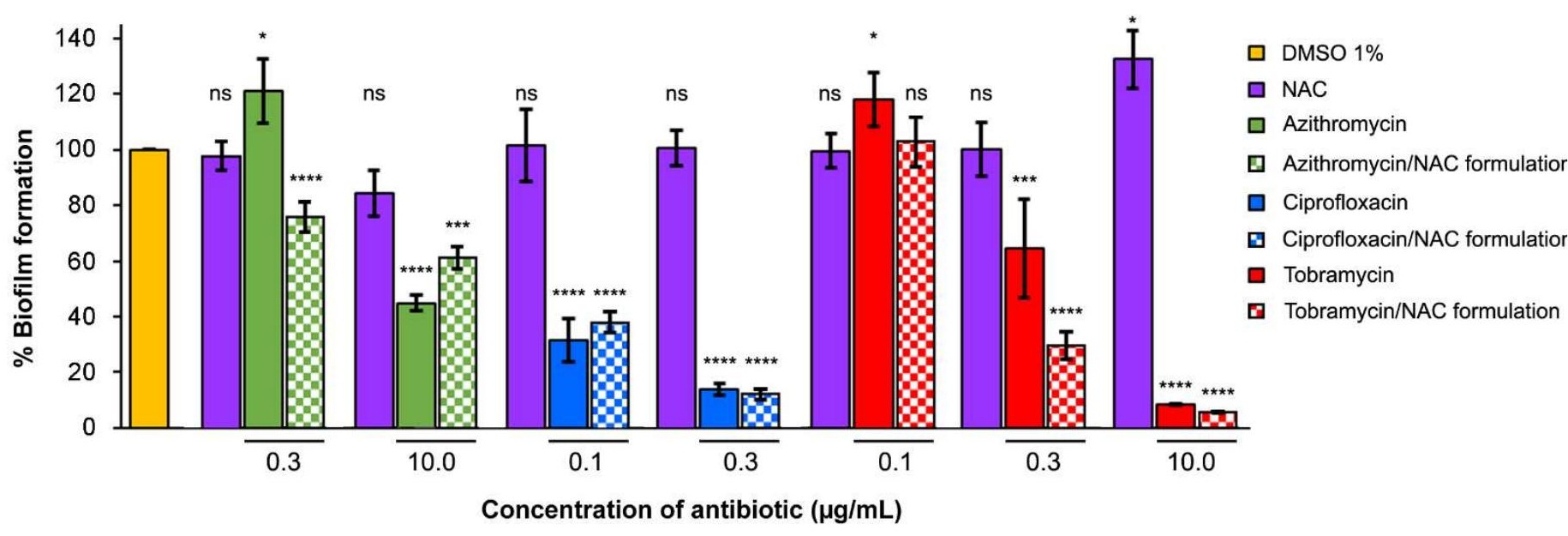

Fig. 8: Effects of the multifunctional DPI formulations at different concentrations on biofilm formation in $P$. aeruginosa PA14. Neat antibiotics and NAC at the same concentrations as in the multifunctional DPI formulations were used as references. ns, not significant; *p $<0.05 ; * * * p<0.001 ;$ and $* * * p<0.0001$ indicate a significant difference ( $t$-test) compared to control. 


\section{Supporting Information}

\section{Spray-drying of inhalable, multifunctional formulations for the treatment of}

biofilms formed in cystic fibrosis

Nashrawan Lababidi ${ }^{1}$, Eric Ofosu. Kissi ${ }^{2,3}$, Walid A. M. Elgaher ${ }^{4}$, Valentin Sigal ${ }^{1}$, Jörg Haupenthal $^{4}$, Bianca C. Schwarz ${ }^{5}$, Anna K. H. Hirsch ${ }^{4,6}$, Thomas Rades ${ }^{3}$, Marc Schneider ${ }^{1} *$

${ }^{1}$ Department of Pharmacy, Biopharmaceutics and Pharmaceutical Technology, Saarland University, Campus C4 1, 66123 Saarbrücken, Germany,

${ }^{2}$ Department of Pharmacy, Faculty of Mathematics and Natural Sciences, University of Oslo, 0316 Oslo, Norway

${ }^{3}$ Department of Pharmacy, Faculty of Health and Medical Science, University of Copenhagen, Universitetsparken 2, DK-2100 Copenhagen, Denmark

${ }^{4}$ Helmholtz Institute for Pharmaceutical Research Saarland (HIPS) - Helmholtz Centre for Infection Research (HZI), Department of Drug Design and Optimization, Campus E8 1, 66123, Saarbrücken, Germany

${ }^{5}$ Pferdeklinik Altforweiler, Raiffeisenstraße 100, 66802 Überherrn, Germany

${ }^{6}$ Department of Pharmacy, Medicinal Chemistry, Saarland University, Campus E8 1, 66123 Saarbrücken, Germany 


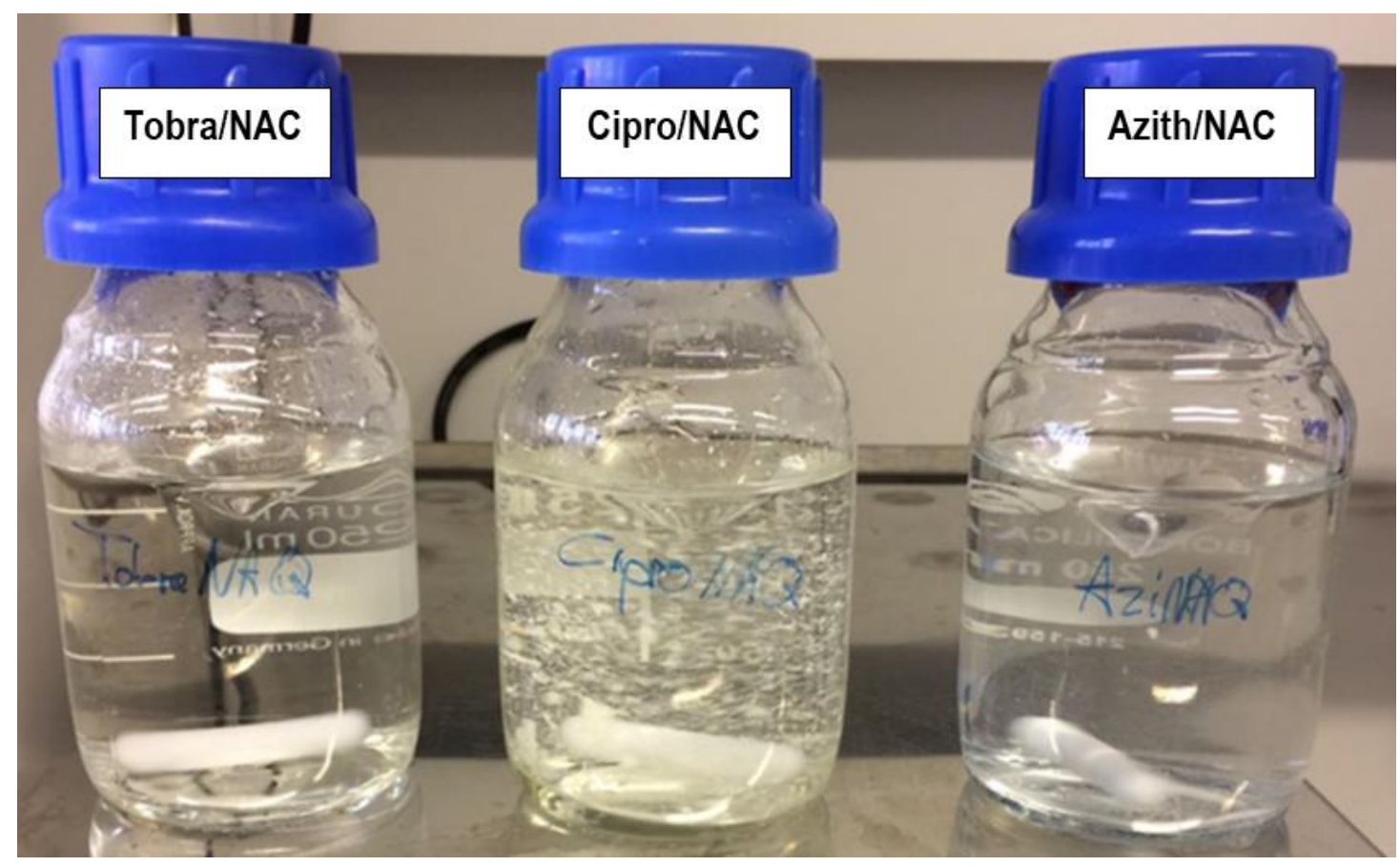

Fig. S1: The dry substances of Tobra/NAC, Cipro/NAC \& Azi/NAC respectively, show differences in dissolving speed upon contact with water. Cipro/NAC takes longer to completely dissolve than the other two formulations. Finally, all formulations were clear solutions after $1 \mathrm{~h}$. Picture was taken 1 min after contact. 
Formulation on the membrane

A

Cipro/NAC

DPI formulation

DPI formulation

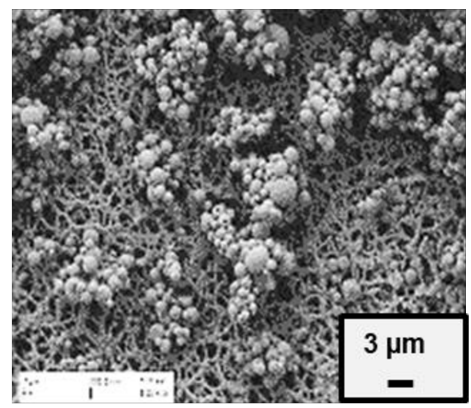

$5 \mathrm{~min}$

B
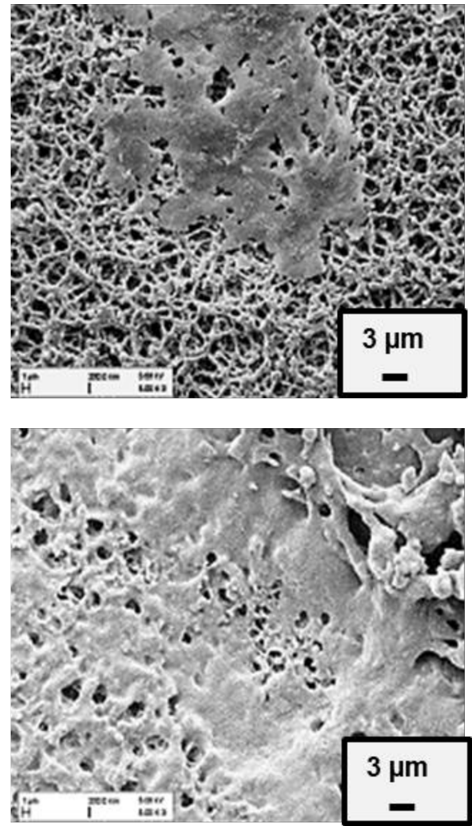

$30 \mathrm{~min}$

C
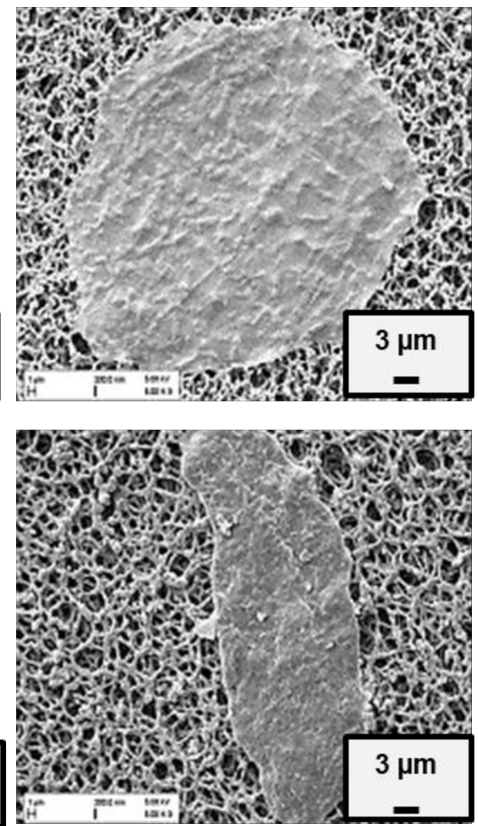

Fig. S2: SEM micrographs of multifunctional DPI formulations deposited on top of a nitrocellulose membrane. (A) formulation on top of the membrane without agarose pad right after deposition, (B) DPI formulations $5 \mathrm{~min}$ after being placed on top of agarose pads, (C) DPI formulations $30 \mathrm{~min}$ after being placed on top of agarose pads. 

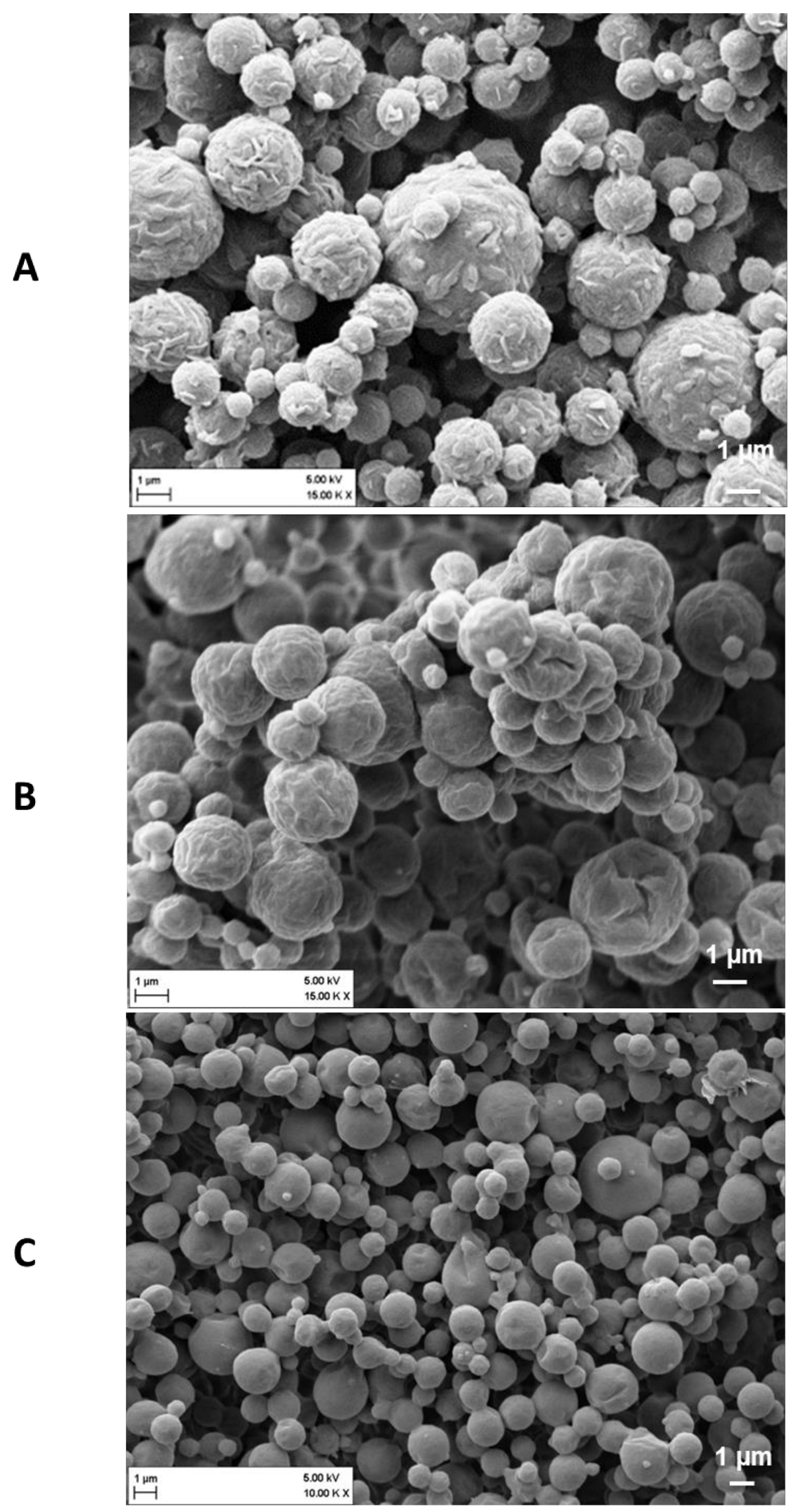

Fig. S3: SEM micrographs of multifunctional DPI formulations (A) Cipro/NAC, (B) Azi/NAC, (C) Tobra/NAC after 3 months. 
Table S1. Antibacterial activities of the neat antibiotics and the antibiotic/NAC DPI formulations.

\begin{tabular}{lccc}
\hline \multirow{2}{*}{ Antibiotic } & Concentration & \multicolumn{2}{c}{ P. aeruginosa PA14 \% inhibition of growth } \\
\cline { 3 - 4 } & $(\mu \mathrm{g} / \mathrm{mL})$ & neat & DPI Formulations \\
\hline Azithromycin & 0.3 & $25 \pm 5$ & $36 \pm 1$ \\
Ciprofloxacin & $0.003-0.1$ & $0.06^{a}$ & $0.05^{a}$ \\
Tobramycin & 0.1 & n.i. $^{b}$ & n.i. \\
Tobramycin & 0.3 & $10 \pm 2$ & $10 \pm 4$ \\
\hline${ }^{a}$ MIC values $(\mu \mathrm{g} / \mathrm{mL})$ were calculated; ${ }^{b}$ n.i. no inhibition.
\end{tabular}

${ }^{a} \mathrm{MIC}$ values $(\mu \mathrm{g} / \mathrm{mL})$ were calculated; ${ }^{b}$.i. no inhibition. 


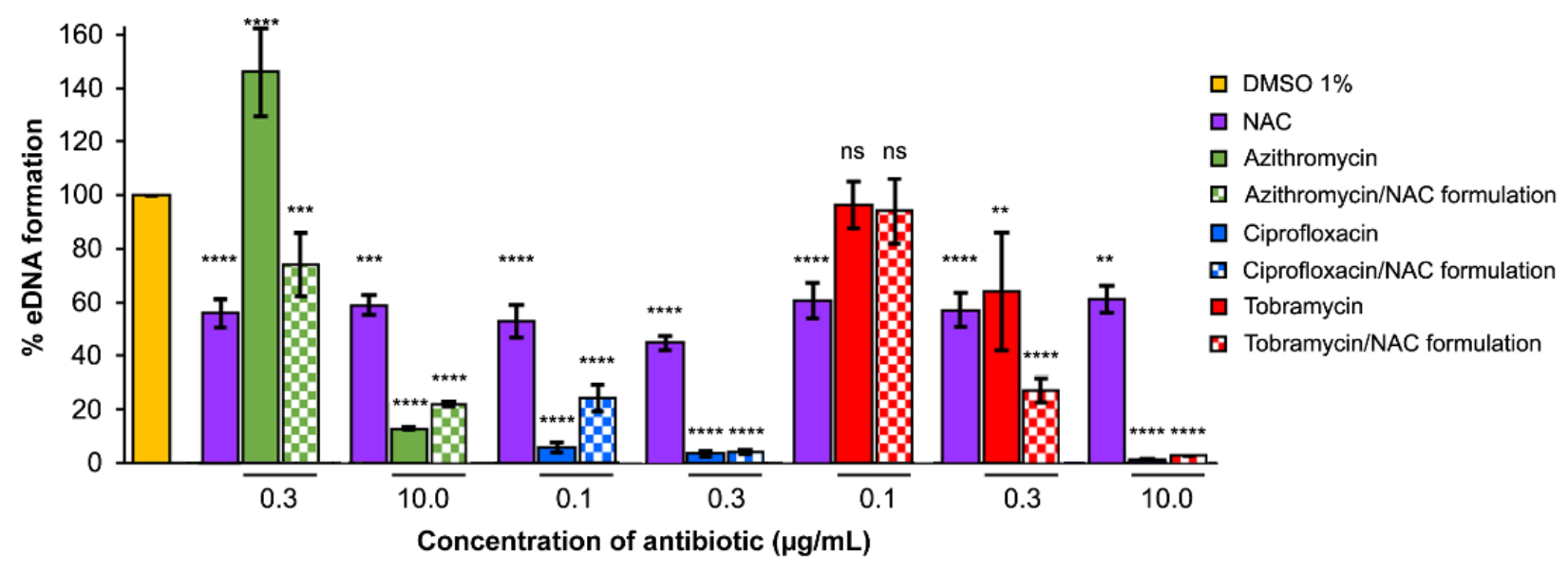

Fig. S4: Effects of the DPI formulations at different concentrations on eDNA formation in $P$. aeruginosa PA14. Neat antibiotics and NAC at the same concentrations as in the multifunctional DPI formulations were used as references. ns, not significant; **p $<0.01$; $* * * p<0.001 ;$ and $* * * * p<0.0001$ indicate a significant difference $(t$-test) compared to control. 

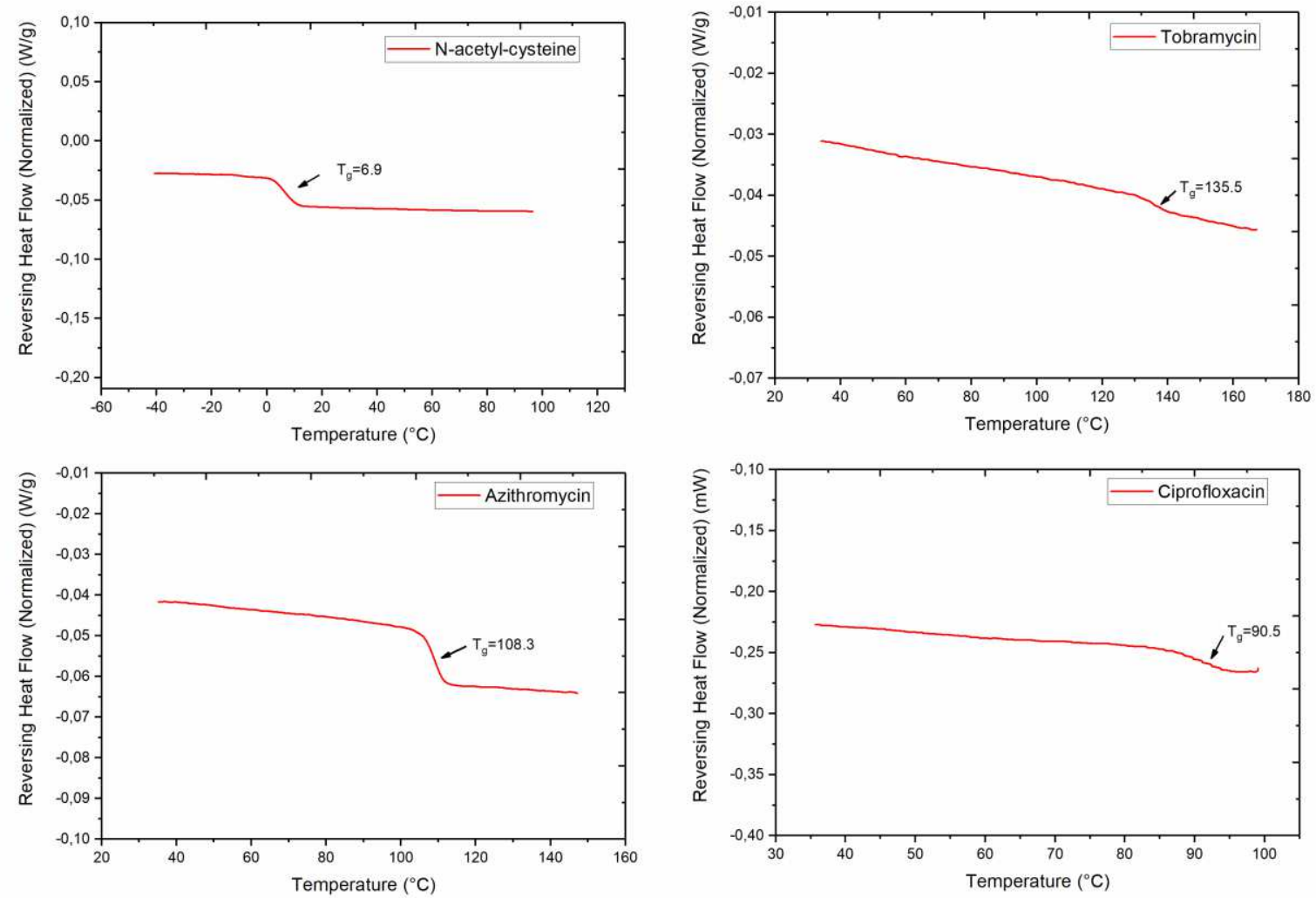

Fig. S5: Thermograms showing the $T_{g s}$ of neat amorphous n-acetyl cysteine, tobramycin, azithromycin and ciprofloxacin. 